MARCELO MICHELE NOVELLINO

Avaliação da estabilidade, por meio da análise da frequência de ressonância, de implantes colocados na maxila posterior variando somente o tratamento de superfície: ensaio clínico randomizado

São Paulo 

Avaliação da estabilidade, por meio da análise da frequência de ressonância, de implantes colocados na maxila posterior variando somente o tratamento de superfície: ensaio clínico randomizado

\section{Versão Corrigida}

Tese apresentada à Faculdade de Odontologia da Universidade de São Paulo, pelo programa de PósGraduação em Ciências Odontológicas para obter o título de Doutor em Ciências Odontológicas

Área de Concentração: Prótese Dentária

Orientadora: Profa. Dra. Dalva Cruz Laganá 
Autorizo a reprodução e divulgação total ou parcial deste trabalho, por qualquer meio convencional ou eletrônico, para fins de estudo e pesquisa, desde que citada a fonte.

Catalogação da Publicação Serviço de Documentação Odontológica

Faculdade de Odontologia da Universidade de São Paulo

Novellino, Marcelo Michele.

Avaliação da estabilidade, por meio da análise da frequência de ressonância, de implantes colocados na maxila posterior variando somente o tratamento de superfície: ensaio clínico randomizado / Marcelo Michele Novellino ; orientador Dalva Cruz Laganá. -- São Paulo, 2017.

85 p. : fig., tab.; graf. ; $30 \mathrm{~cm}$.

Tese (Doutorado) -- Programa de Pós-Graduação em Ciências Odontológicas. Área de Concentração: Prótese Dentária. -- Faculdade de Odontologia da Universidade de São Paulo.

Versão corrigida.

1. Tratamento de superfícies - Odontologia . 2. Ensaio clínico controlado randomizado. 3. Cicatrização. 4. Osseointegração. - I. Laganá, Dalva Cruz. II. Título. 
Novellino MM. Avaliação da estabilidade, por meio da análise da frequência de ressonância, de implantes colocados na maxila posterior variando somente o tratamento de superfície: ensaio clínico randomizado. Tese apresentada à Faculdade de Odontologia da Universidade de São Paulo para a obtenção do título de Doutor em Ciências Odontológicas.

Aprovado em: 03/05/2018

\section{Banca Examinadora}

Prof(a). Dr(a). Raquel Virgínia Zanetti

Instituição: São Leopoldo Mandic Julgamento: Aprovado

Prof(a). Dr(a). Renata Cunha Matheus Rodrigues Garcia

Instituição: Depto. de Prótese FOP - Unicamp Julgamento: Aprovado

Prof(a). Dr(a). Maria da Graça Naclerio Homem

Instituição: Depto. de Cirurgia - FOUSP Julgamento: Aprovado 

Dedico esse trabalho à Julia e Rafaela pelo sorriso de todas as manhãs. São o meu maior tesouro e o motivo de todos os esforços.

À Adriana pelo amor, compreensão, incentivo e dedicação à família que formamos. Minha melhor amiga que sempre deu seu apoio.

Aos meus pais, pelo amor, dedicação empregada na formação do meu carácter e incentivo na minha formação profissional.

Aos meus irmãos pela união que nos faz uma família. 



\section{AGRADECIMENTOS}

À Professora Dalva Cruz Laganá por ter acreditado em mim no mestrado e novamente agora no doutorado. Pela sua dedicação aos seus alunos, abordagem sincera, honestidade e generosidade com a qual empresta seus vastos conhecimentos na área de prótese e na arte de ensinar.

À Universidade de São Paulo, onde fiz a graduação, o mestrado e agora o doutorado.

À Faculdade de Odontologia, na pessoa do Diretor, Prof. Dr. Rodney Garcia Rocha.

À Comissão de Pós Graduação, representada pelo Prof. Dr. Edgar Michel Crossato.

Ao Departamento de Prótese, seus professores e funcionários.

Ao Centro de Excelência em Prótese e Implante da FOUSP (CEPI) por fornecer o espaço e as condições para a realização da pesquisa.

À Biblioteca da Faculdade de Odontologia da USP, pelo auxílio na diagramação.

Aos colegas do curso e do Departamento pela amizade sincera, troca de conhecimento e pelas discussões sempre produtivas. Em especial ao Piero Rocha Zanardi pela colaboração com o trabalho.

À Neodent pelo fornecimento de materiais e auxílio técnico. 



\section{RESUMO}

Novellino, MM. Avaliação da estabilidade, por meio da análise da frequência de ressonância (RFA), de implantes colocados na maxila posterior variando somente o tratamento de superfície: ensaio clínico randomizado [tese] São Paulo: Universidade de São Paulo, Faculdade de Odontologia; 2017. Versão Corrigida.

Contexto: Modificações químicas da superfície dos implantes dentários com o objetivo de aumentar a molhabilidade resultam em uma osseointegração mais rápida e melhor. Objetivo: O objetivo deste estudo foi avaliar o quociente de estabilidade do implante (ISQ) (implant stability quotient) de implantes com geometria idêntica, mas com tratamentos de superfície diferentes: jateamento de areia e ataque ácido (SAE) e a mesma superfície com uma modificação química para aumento da hidrofilia, dentro das primeiras 16 semanas de cicatrização. Materiais e Método: neste estudo clínico randomizado um total de 64 implantes (32 SAE - Grupo Controle e 32 SAE modificado - Grupo Teste) com o mesmo desenho geométrico, comprimento e diâmetro (cônico e compressivo, 4,3×10 mm) foram colocados na maxila posterior de 21 pacientes parcialmente desdentados. Os valores de ISQ foram coletados no pós - cirúrgico imediato (T0), com 1 semana (T1), 2 (T2), 3 (T3), 5 ( T4), 8 (T5), 12 (T6) e 16 semanas (T7). Os resultados foram comparados por meio do ANOVA de medidas repetidas. Resultados: O grupo teste apresentou valores de ISQ mais altos que o grupo controle (ANOVA - $p<0,01$ ) a partir da $5^{a}$ semana. Quando comparados os grupos em relação ao tempo necessário para se atingir o ISQ $\geq 70$ como uma referência, houve uma diferença estatisticamente significante $(p<0,01)$ e um Hazard Ratio de 2,24 (IC 1,62-3,11). No acompanhamento de um ano um paciente com 2 implantes abandonou a pesquisa, e estes não puderam mais ser avaliados. $A$ taxa de sobrevida de ambos grupos foi de 100\% após um ano de acompanhamento. Conclusão: O presente estudo sugere que implantes com superfície hidrofílica osseointegram mais rápido que implantes com superfície SAE convencional. O ganho de estabilidade do grupo teste foi 2,24 vezes mais rápido que do grupo controle após 5 semanas de avaliação em leitos na maxila posterior.

Palavras Chave: Pesquisa clínica. Estabilidade do implante. Tratamento de superfície. Ensaio clínico randomizado. Propriedades da superfície. 



\begin{abstract}
Novellino, MM. Stability evaluation, through resonance frequency analysis (RFA), of implants placed in the posterior maxilla varying only the surface treatments: randomized clinical trial [thesis] São Paulo: Universidade de São Paulo, Faculdade de Odontologia; 2017. Versão Corrigida.
\end{abstract}

Background: Chemical modifications of dental implant surface, to improve the wettability, results in a faster and better osseointegration. Purpose: The aim of this study was to evaluate the implant stability quotient (ISQ) of implants with the same design, treated with two different surfaces: Sandblasted Acid-Etched (SAE) and hydrophilic SAE, within the initial 16 weeks of healing. Materials and Method: For this RCT a total of 64 implants (32 SAE - Control Group and 32 modified SAE - Test Group) with the same design, length and diameter (conical and compressive, $4.3 \times 10$ $\mathrm{mm}$ ) were inserted in the posterior maxillae of 21 patients partially edentulous. The ISQ values were collected at the post-surgery (T0), 1-week (T1), 2-weeks (T2), 3weeks (T3), 5-weeks (T4), 8-weeks (T5), 12-weeks (T6) and 16-weeks (T7). The statistic test was ANOVA. Results: Test group presented ISQ values higher than the Control group (ANOVA $-\mathrm{p}<0.01$ ) from $5^{\text {th }}$ week. When comparing groups regarding the amount of time required to achieve ISQ $\geq 70$ as a reference, there was a statistically significant difference ( $p<0.01)$, and a HR (Hazard Ratio) of 2.24 (Cl 1.623.11). At the one-year follow up, there was a drop out of one patient and two implants were no longer evaluated. Survival rate for both groups was of $100 \%$ after one year of follow up. Conclusion: The current study suggests that implants with hydrophilic surface (modified SAE) integrates faster than implants with SAE surface. Stability gain of the tested group was 2.24 times faster than the control group after five weeks of evaluation at the posterior region of maxillae.

Keywords: Clinical research. Implant stability. Implant surface. Randomized controlled trail. Surface properties. 

1 INTRODUÇÃO

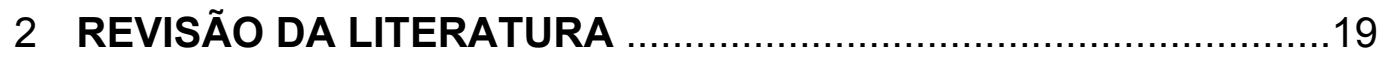

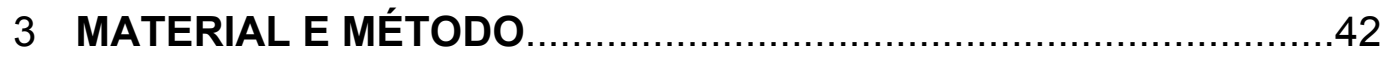

4 RESULTADOS

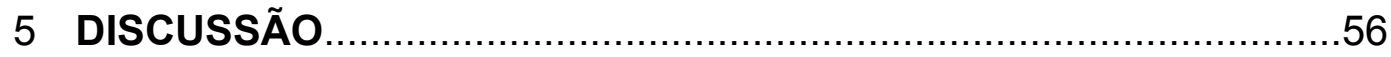

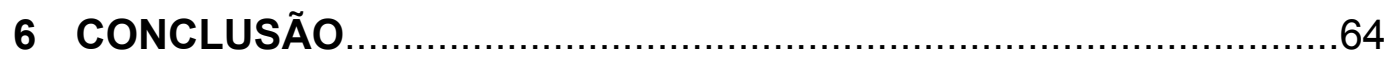

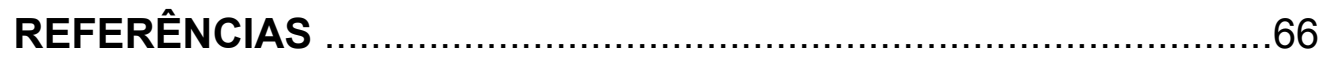

ANEXOS 



\section{INTRODUÇÃO}

A substituição de dentes por próteses implanto-suportadas nas reabilitações orais é um tratamento previsível baseado em mais de 50 anos de experiência clínica e, em uma série de pesquisas, com grande tempo de acompanhamento (1). Atualmente muitos estudos buscam a melhoria da osseointegração, das interfaces protéticas e de um desenho geométrico que proporcione maior estabilidade mesmo em condições adversas e desafiadoras e, com o objetivo de reduzir o tempo de espera para a reabilitação, a morbidade de procedimentos mais invasivos e 0 número de intervenções necessárias.

No final dos anos 70 foram publicados artigos sobre o fenômeno da osseointegração utilizando implantes de titânio com superfícies tratadas com plasma de titânio (2). O tratamento de superfície, desde o início da implantodontia, merecia uma atenção especial face aos benefícios que essa modificação poderia trazer para a osseointegração em relação aos implantes apenas usinados (3). A superfície do implante, incluindo a sua topografia, composição química, a carga elétrica e molhabilidade, tem sido descrita como fator importante para o aperfeiçoamento do processo da osseointegração (4) (5).

Diversos tipos de tratamento de superfície do titânio foram introduzidos no mercado sempre buscando a melhoria da osseointegração e a redução do tempo para alcançá-la. Sua modificação física e ou química induz maior rapidez na deposição de tecido ósseo sobre o implante, possibilitando, desta forma, o carregamento precoce (6) e a reabilitação protética em menor tempo, reduzindo custos com a manutenção de próteses temporárias. $O$ tratamento de superfície é a base biológica para os protocolos de carregamento precoce de implantes (7).

Além do benefício do carregamento em tempo reduzido, os diversos tipos de tratamento de superfície do implante possibilitam uma melhor integração do osso com o implante, permitindo, em alguns casos, a reabilitação de espaços protéticos sem a necessidade de recursos mais invasivos e com maior morbidade, como levantamento do assoalho do seio maxilar, lateralização do nervo alveolar inferior ou enxertos em bloco, pois implantes com tamanho e diâmetro reduzidos podem ser utilizados sem comprometimento de suas funções $(8,9)$. 
Implantes com superfície do tipo SAE (sandblasted and acid-etched) apresentam, em condições ósseas normais, uma osseointegração mais rápida quando comparados com implantes de superfície apenas usinada $(4,10)$. Essa mesma superfície, em situações normais, pode ser carregada após 6 a 8 semanas e com elevadas taxas de sucesso (11-13).

Já implantes com superfícies SAE quimicamente modificadas para o aumento de sua molhabilidade podem ser carregados em até 3 semanas em condições normais $(12,13)$. Essa superfície, também chamada de superfície hidrofílica ou super-hidrofílica tem demonstrado um aumento do contato entre o osso do hospedeiro e a superfície do implante (BIC) em diversos estudos com animais (14). Apresenta ainda características físico-químicas especiais, como menor concentração de Carbono e maior de Oxigênio $(14,15)$. A sua maior molhabilidade favorece as interações celulares que ocorrem na interface hospedeiro/implante, aprimorando a diferenciação osteogênica das células tronco mesenquimais e osteoblastos. Tem efeitos positivos sobre as células em relação à ligação, proliferação, diferenciação e expressão genética quando comparada a outros tratamentos de superfície (14).

A estabilidade de um implante pode ser definida como ausência de mobilidade clínica, o que também pode ser sugerido como uma definição para a osseointegração (16). Atingir e manter a estabilidade dos implantes são prérequisitos para se obter sucesso nessa terapia $(17,18)$. Assim, é importante possibilitar que a estabilidade seja objetivamente mensurada, permitindo quantificála em diversos momentos após a instalação dos implantes (19). Com o objetivo de avaliar métodos que pudessem determinar a estabilidade dos implantes, tanto com finalidade em pesquisa ou prognóstico, Meredith em 1996, desenvolveu a Análise de Frequência de Ressonância (RFA) (20). A RFA fornece uma medida objetiva da estabilidade dos implantes, sem contudo, prejudicar o processo de osseointegração que está ocorrendo na interface osso/implante (18). Atualmente a RFA é extensamente utilizada em pesquisas clínicas para monitorar a estabilidade dos implantes (18).

O tratamento de superfície do titânio permite uma melhor e mais rápida osseointegração; aprimoramentos nesta área podem proporcionar reabilitações mais rápidas e em regiões que no passado ou eram submetidas às próteses tradicionais ou a tratamentos cirúrgicos com maior morbidade, pois uma osseointegração mais eficaz permite a redução do diâmetro e do comprimento de implantes, possibilitando 
o uso desses dispositivos em áreas com pouca quantidade de tecido ósseo. A melhor osseointegração obtida com superfícies de melhor qualidade permite maior previsibilidade e sucesso neste tipo de tratamento. Justifica-se portanto a realização de estudos sobre modificações na superfície do titânio com o intuito de acelerar o processo de osseointegração e aprimorá-lo, buscando taxas mais elevadas no percentual de contato entre osso e implante (BIC).

Como a superfície hidrofilica pode acelerar e melhorar a osseointegração, aumentando o valor do percentual de BIC e possibilitando alcançar mais rapidamente a estabilidade secundária, foi objetivo deste estudo avaliar se implantes com superfície com maior molhabilidade, produzidos por uma empresa brasileira, (Acqua, Neodent, Curitiba, Brasil) apresentam ganho de estabilidade secundária de forma mais rápida que implantes com superfície do tipo SAE (Neoporos, Neodent, Curitiba, Brasil), por meio da análise de frequência de ressonância (RFA) em um ensaio clínico randomizado de acordo com as diretrizes do CONSORT (21) 





\section{REVISÃO DA LITERATURA}

\subsection{A estabilidade e a RFA}

Entre os critérios estabelecidos por Albrektsson (22) para se alcançar e manter a osseointegração está a estabilidade primária. Quando o implante é instalado a estabilidade obtida está relacionada à quantidade do contato mecânico entre o osso e o implante, não havendo ainda neste momento nenhum tipo de conexão biológica entre implante e osso adjacente, ou seja, a estabilidade inicial reflete o grau de intertravamento mecânico entre as duas estruturas (implante e osso). A denominada estabilidade primária é um pré-requisito e um preditor do sucesso da osseointegração. Esta limita o micro-movimento o que é favorável à osseointegração, pois a baixa estabilidade leva à encapsulação fibrosa e a consequente falha na osseointegração. A estabilidade primária, ligação mecânica do implante ao osso, diminui com o tempo até ser substituída pela estabilidade secundária (ou biológica) que é um mecanismo biológico que envolve um complexo processo de formação óssea, maturação e remodelação na interface implante e osso, processos denominados osseointegração e remodelação óssea (23-26).

O sucesso do tratamento com implantes depende muito da estabilidade primária e esta é influenciada pelo comprimento do implante, seu diâmetro, forma, desenho de rosca, da técnica cirúrgica e do tipo de osso do leito receptor (27). Regiões de osso menos denso e trabecular, como a maxila posterior, podem direta ou indiretamente afetar a estabilidade primária (mecânica) dos implantes. O desenho e as propriedades da superfície do implante são características que contribuem para o processo (25). Tanto a estabilidade primária quanto a secundária são afetadas pela rugosidade superficial, já que uma superfície rugosa aumenta o intertravamento entre implante e o osso adjacente. Embora esta seja obviamente mais relevante na obtenção da estabilidade secundária $(28,29)$.

Segundo Sim \& Lang (30) a análise de frequência de ressonância (RFA) foi descrita pela primeira vez como método clínico de mensuração da estabilidade de implantes em 1996 por Meredith et al. (30) A RFA é um método comprovado que permite aos pesquisadores quantificarem a estabilidade de implantes no momento da instalação e no subsequente acompanhamento (31). A RFA permite avaliar as 
mudanças na estabilidade do implante ao longo do tempo, de maneira clinica e nãoinvasiva (26). O sistema Osstell Implant Stability Quocient (ISQ) (Osstel AB, Gotemburgo, Suécia) utiliza a RFA para mensurar a rigidez na interface ossoimplante utilizando um transdutor conectado ao implante ou ao componente protético. Os valores de ISQ são de 1 a 100, objetivamente (32). O aumento do ISQ está relacionado com o aumento da rigidez da interface entre implante e osso adjacente. As medidas de RFA/ISQ são usadas para documentar alterações durante o período de osseointegração e identificar os implantes sob o risco de falhar (28, 30). Muitos estudos demonstraram que a RFA/ISQ é um indicador confiável da estabilidade e sucesso de implantes. Ela pode ser utilizada para monitorar alterações na rigidez e estabilidade de implantes e assim predizer a probabilidade de sucesso ou falha na osseointegração $(30,31,33,34)$. Os dados de ISQ permitem em tempo real comparações da estabilidade de implantes com o processo de osseointegração em curso, e a alteração da estabilidade mecânica para a biológica (23). Quando o valor de ISQ excede 65 no momento da colocação do implante a taxa de sobrevida desse implante será de $99 \%$, os valores superiores a 60 de ISQ foram considerados preditores de sucesso $(17,35,36)$. (Figura 2.1)

Figura 2.1 - Correlação entre os valores de ISQ e a estabilidade do implante. Osstell website (www.osstell.com)

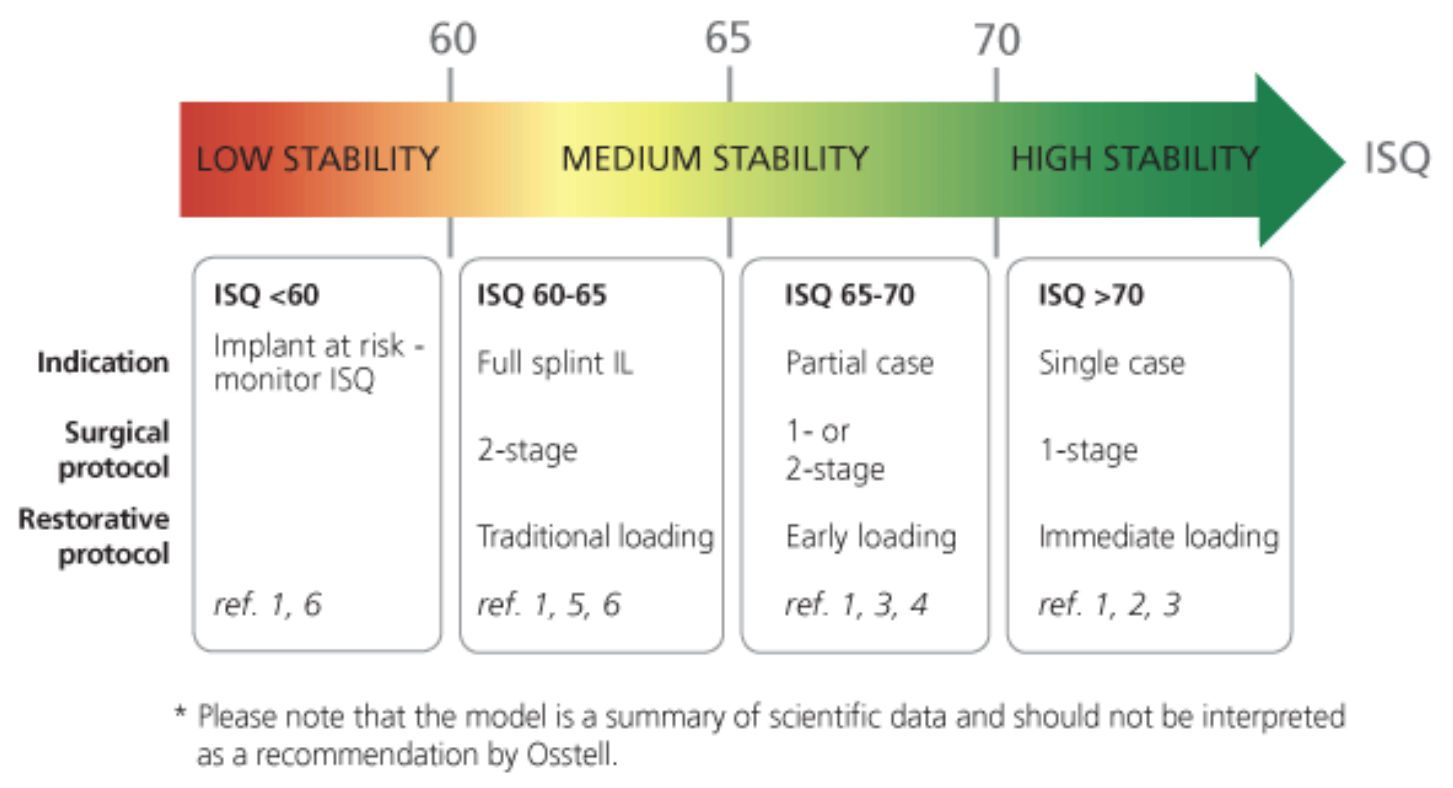


Sim \& Lang (30) citando Sennerby et al. afirmaram que valores de ISQ significativamente mais elevados foram encontrados em sítios implantares na mandíbula que em sítios na maxila no pós cirúrgico imediato. Os valores de ISQ tiveram elevação continua e no final de um período de 6 meses, não foram encontradas diferenças estatisticamente significantes entre os valores encontrados na maxila e mandíbula. O estudo ainda demonstrou que implantes com baixa estabilidade primária na instalação apresentaram um grande aumento dos valores de ISQ até o momento da instalação do pilar protético quando comparados com implantes que apresentaram um alto nível de estabilidade primária inicial (30).

Kunnekel et al.(20) realizaram um estudo para determinar a relação entre os valores de ISQ obtidos por meio da RFA e a distância implante/osso medida histomorfometricamente. Dez implantes idênticos foram colocados em fêmur de cabra, metade com a osteotomia determinada pelo fabricante e outra metade com a osteotomia maior que a necessária, simulando uma baixa estabilidade. Os valores de ISQ foram obtidos e depois a distância implante/osso foi determinada por microscopia. Com os resultados obtidos foi possível concluir que a RFA pode ser usada para determinar a estabilidade do implante com segurança (20).

Foi realizado um estudo com o objetivo de monitorar a evolução da estabilidade de implantes com desenho geométrico que apresenta baixa estabilidade inicial e superfície SAE (Tissue-level, SLA, Straumann, Basel, Suíça) usando a RFA e assim determinar a influência do posicionamento do dispositivo Ostell, da estrutura óssea e do comprimento do implante na avaliação da RFA. Para tanto foram selecionados 32 adultos saudáveis que receberam implantes com 4,1 mm de diâmetro e $8 \mathrm{~mm}$ altura (grupo A) e 4,1 mm de diâmetro e $10 \mathrm{~mm}$ de altura (grupo B). Durante a cicatrização os implantes foram avaliados nas semanas 0, 1, 2, 3, 4, 5, 6, 8, 12. Foram avaliadas ainda a sondagem periodontal, presença de placa e sangramento a sondagem. Concluíram que o posicionamento do Ostell não afeta os valores de ISQ. Os valores de ISQ são afetados pela estrutura óssea e pelo comprimento do implante. E nenhum valor de ISQ pode ser definido para assegurar a estabilidade dos implantes (30).

A vantagem de métodos como a análise de frequência de ressonância (RFA) é que este é uma forma de se obter uma medida quantitativa, não invasiva e não destrutiva, da integração do implante, e permitir a avaliação das alterações da estabilidade do implante ao longo do tempo. Já a análise histológica, que é uma 
outra forma de avaliar a cicatrização óssea ao redor de implantes e determinar a evolução da estabilidade secundária, é um processo muitas vezes inviável por ser invasivo e destrutivo.

Outros métodos foram desenvolvidos para avaliar a resposta implante/osso, como, por exemplo, a tomografia micro-computadorizada (micro-CT), este um procedimento não destrutivo, baseado em tecnologia radiográfica e permite uma avaliação tridimensional. Um estudo comparou implantes com superfície SAE modificada para aumento da molhabilidade (SLActive, Straumann, Basiléia, Suíça) e implantes de superfície modificada por nano partículas de hidroxiapatita (Nanotite, 3i, Flórida, Estados Unidos). Após 2, 4 e 8 semanas da colocação de implantes em mandíbulas de cães, análises de RFA e Micro-CT foram feitas para avaliar a estabilidade e o grau de cicatrização óssea dos implantes. O estudo demonstrou que implantes do tipo SAE modificada (SLActive) e com nano partículas de hidroxiapatita (NanoTite) apresentaram estabilidade primária e secundária após 2, 4 e 8 semanas similares em mandíbulas de cães. Os dados confirmaram que RFA é um meio viável de determinar a estabilidade de implantes e acompanhar o processo de cicatrização e remodelação óssea de forma não invasiva. Os dois implantes (SLActive e NanoTite) apresentaram respostas ósseas similares após a instalação, 2, 4 e 8 semanas em mandíbulas de cães quando avaliados pela tomografia microcomputadorizada (28).

Outro estudo relacionou a densidade óssea de leitos implantares determinada por tomografia de feixe cônico (CBCT) e a relacionou com idade, gênero, torque de inserção e análise de frequência de ressonância. A densidade óssea foi avaliada por meio da escala Hounsfield em tomografias pré-operatórias, o torque de inserção e as medidas de RFA também foram registrados. Segundo os autores, as medidas de densidade óssea por meio da CBCT podem ser úteis, especialmente quando em conjunto com os valores de RFA e medidas de torque de inserção (37).

Supondo que a orientação do transdutor do Ostell (mésio-distal e bucolingual) afetaria os dados de RFA obtidos, Park et al. realizaram um estudo clinico prospectivo para avaliar se é necessário utilizar 2 medidas feitas em 2 orientações diferentes para se obter dados sobre a rigidez de implantes. Selecionaram 53 pacientes e utilizaram implantes de $4,1 \mathrm{~mm}$ por $10 \mathrm{~mm}$, a RFA foi medida no ato cirúrgico e com 4 e 10 semanas. As medidas foram tomadas 2 vezes em cada direção: mesial na direção mésio-distal e por vestibular na direção buco-lingual. A 
média de cada medida foi utilizada para cada direção. Concluíram que a aquisição de 2 medidas de ISQ e a classificação dos valores mais altos e mais baixos permitem ao clinico obter dados que uma única medida ignora (19).

O método de avaliação clinica da estabilidade dos implantes, embora simples, é muito subjetivo. Para Romanos et al. os outros métodos de avaliação da estabilidade, como o Periotest e Osstell (RFA), são similares e não demonstram ser métodos ideais (27). Já segundo Atieh et al. o Osstell é superior ao Periotest em precisão e tem dominado as pesquisas em implantodontia. $\mathrm{O}$ dispositivo Osstell pode ser útil no monitoramento da estabilidade após a instalação e durante o período de osseointegração, mas para o caso específico da carga imediata a única medição possível é no momento da instalação, confirmando ou não a possibilidade da realização de tal procedimento, indicando a estabilidade primária do implante, sendo impossível monitorar o implante no período da osseointegração, o que compromete a utilidade do dispositivo para esta tarefa especificamente (24). No momento da instalação do implante, apenas a medida do ISQ não é suficiente para determinar a estabilidade para procedimentos de carga imediata. Deve-se utilizá-la combinada com outros parâmetros clínicos, como avaliações radiográficas e análise do torque de inserção (24).

Ersanli et al. realizaram um estudo para determinar o quanto a tecnologia RFA poderia ser integrada à rotina clinica de avaliação da osseointegração de implantes dentários. Para tanto instalaram 122 implantes em 31 pacientes. Os resultados suportam a necessidade de uma ferramenta clínica capaz de avaliar a estabilidade dos implantes antes do seu carregamento protético, especialmente para os implantes colocados na maxila. Os implantes parecem apresentar menor nível de estabilidade entre a $3^{\mathrm{a}}$ e $6^{\mathrm{a}}$ semanas após a instalação (38).

Segundo Degidi et al. valores de ISQ poderiam estar relacionados com a porcentagem de osso mineralizado na interface implante/osso (MBIC - mineralized bone-implant contact). Para confirmar tal hipótese realizaram um estudo onde compararam os valores de RFA e de MBIC de implantes removidos de humanos após o período de 4 a 8 semanas. Eles utilizaram um arquivo de implantes removidos na Universidade de Chieti-Pescara, Itália. Os implantes foram removidos por motivos protéticos e todos tinham no máximo 8 semanas de pós-cirúrgico. Todos os implantes foram avaliados por meio da RFA (Ostell) no momento anterior à sua remoção. Todos os implantes eram do tipo SAE, podendo ser SAE modificado e 
todos estavam clinicamente osseointegrados, não havendo mobilidade. Além da RFA, os implantes após a remoção foram avaliados histomorfologicamente. Os autores concluíram que a relação entre a estrutura óssea e a RFA não é totalmente compreendida, no entanto, a estabilidade primária pode ser influenciada não só pela densidade óssea, mas também pela espessura e densidade da camada cortical (39).

Ostman et al. avaliaram a estabilidade primária por meio do Ostell de implantes colocados segundo um protocolo cirúrgico voltado ao aumento da estabilidade inicial. Também avaliaram a correlação entre as medidas de RFA com fatores relativos à técnica cirúrgica, ao paciente e ao desenho do implante. Foram colocados 905 implantes em 267 pacientes e as medidas com a RFA foram feitas no pós-cirúrgico imediato. A média do ISQ foi de $67,4 \pm 8,6$ para todos os implantes. Os autores encontraram valores mais altos para os homens em relação às mulheres, na mandíbula em relação à maxila, em regiões posteriores em relação às anteriores e para os implantes de maior diâmetro em relação aos regulares ou estreitos. Os autores ainda conseguiram fazer uma correlação entre a qualidade óssea e a estabilidade primária, com baixos valores de ISQ para os implantes colocados em osso menos denso. Ainda afirmam que mais baixa estabilidade é obtida quando se reduz o comprimento dos implantes. Concluíram que a densidade óssea e as características do implante afetam a estabilidade primária. $\mathrm{O}$ uso de sub-fresagem e implantes cônicos não conseguiu compensar completamente os efeitos negativos do osso menos denso sobre a estabilidade primária (40).

No início a análise de frequência de ressonância (RFA), que permite uma avaliação não invasiva da estabilidade de implantes, utilizava um sistema eletrônico o qual foi trocado mais recentemente por um sistema que utilizada tecnologia magnética. Valderrama et al. realizaram um estudo clínico comparando as duas tecnologias e avaliaram a habilidade do sistema RFA magnético em detectar mudanças na estabilidade durante as fases iniciais da cicatrização. A RFA foi utilizada nas duas tecnologias para avaliar a estabilidade de 34 implantes não submersos em 17 pacientes. Os implantes foram avaliados no pós operatório e semanalmente até a $6^{a}$ semana, quando receberam provisórios sobre estes implantes, então foram reavaliados na $12^{\mathrm{a}}$ semana. $\mathrm{Na}$ colocação dos implantes o sistema eletrônico apresentou um ISQ médio de 61,9 chegando a 63,2 na $12^{\text {a }}$ semana. Para a tecnologia magnética, a média do ISQ na instalação foi de 70,6 e chegou a 75,9, respectivamente. Para os 2 dispositivos houve um padrão de queda 
do valor do ISQ da $1^{\text {a }}$ a $3^{\text {a }}$ semana após a instalação, depois pequena flutuação dos valores de ISQ entre a $3^{\mathrm{a}}$ e $6^{\mathrm{a}}$ semana e um significante aumento de estabilidade entre a $6^{\mathrm{a}}$ e $12^{\mathrm{a}}$ semanas. Ambos dispositivos confirmaram a redução do valor do ISQ inicial após a instalação e identificaram um ganho de estabilidade nas 6 semanas com carga funcional (41).

Huwller et al. monitoraram a RFA em relação as características ósseas dos maxilares durante as fases iniciais da reparação e incorporação de implantes com superfície SAE (Straumann - SLA). Vinte e quatro implantes (17 com 4,1 $\mathrm{mm}$ de diâmetro por $10 \mathrm{~mm}$ de comprimento e $7 \mathrm{com} \mathrm{4,8} \mathrm{mm} \mathrm{de} \mathrm{diâmetro} \mathrm{e} 10 \mathrm{~mm}$ de comprimento) foram instalados e o ISQ determinado na instalação (baseline) e após 1, 2, 3, 4, 5, 6, 8 e 12 semanas. O tecido ósseo dos pacientes foi avaliado por tomografia computadorizada. O ISQ no baseline variou de 55 a 74 com média de 61,4 para os implantes de $4,1 \mathrm{~mm}$ de diâmetro e para os de $4,8 \mathrm{~mm}$ o ISQ foi de 57 a 70 (média 63,3 ). No período da osseointegração o ISQ subiu na $1^{\text {a }}$ semana e caiu entre a $2^{\mathrm{a}}$ e $3^{\mathrm{a}}$ semanas e a partir da $4^{\mathrm{a}}$ semana voltou a subir (42).

Segundo Van Eekeren et al. muitos estudos avaliaram as medidas de ISQ no momento da instalação e após a osseointegração dos implantes. Tais medidas não permitem determinar o padrão no qual a estabilidade dos implantes se desenvolve, pois mensurações mais frequentes são necessárias para a obtenção destas informações. Os autores realizaram um estudo com o objetivo de avaliar o desenvolvimento da estabilidade de implantes com superfície hidrofilica durante a osseointegração. Um total de 76 implantes foi instalado em 32 pacientes, 20 na maxila e 56 na mandíbula. A média do ISQ foi de $74 \pm 4,2$ no momento da instalação. A média do ISQ na segunda semana foi significativamente menor, a partir da terceira semana o valor de ISQ voltou a subir e foi significativamente maior na $12^{\text {a }}$ semana. Segundo os autores essa queda significativa na segunda semana dos valores de ISQ corresponde ao processo de perda da retenção mecânica nas fases iniciais da osseointegração. $O$ aumento gradual a partir da $3^{a}$ semana indicou a formação de osso novo. De acordo com os autores, a queda referente a perda da estabilidade primária é mais rápida em implantes com a superfície hidrofílica, normalmente na segunda semana e para implantes com superfície hidrofóbica essa queda é por volta da $3^{\mathrm{a}}$ ou $4^{\mathrm{a}}$ semana. Os autores ainda comentaram que a RFA e a mensuração do torque de inserção estão entre os poucos parâmetros clínicos e não invasivos que podem ser usados para uma análise qualitativa da osseointegração, 
sendo que o torque de inserção só pode ser analisado no momento da instalação dos implantes, já a RFA pode ser obtida em qualquer momento após a colocação. Para finalizar, os autores conseguiram demonstrar uma alta correlação entre o torque de inserção e a estabilidade dos implantes(26).

Simunek et al. publicaram um estudo com o objetivo de monitorar o desenvolvimento da estabilidade de implantes nas fases iniciais da osseointegração. Para tanto, colocaram 90 implantes na região interforaminal, a estabilidade foi avaliada na instalação e nas semanas $1,2,3,4,5,6,8,10$ após a instalação utilizando a RFA. A queda mais pronunciada dos valores de ISQ ocorreu na primeira semana após a instalação dos implantes. Os autores concluíram que implantes que apresentaram baixos valores de estabilidade primária demonstraram um significativo aumento de estabilidade durante a osseointegração, já implantes com alta estabilidade primária perderam alguma estabilidade ao longo do tempo (43).

Park et al. realizaram um estudo com o objetivo de relacionar os valores de ISQ com os valores de BIC\% (bone to implant contact ratio) em coelhos. Os autores correlacionaram os valores de ISQ obtidos na instalação e no momento do sacrifício dos animais com os valores de BIC\% obtidos na análise histomorfométrica realizada, concluíram que RFA é um método clínico útil para prever os valores de BIC\% e a estabilidade dos implantes (44). Trabalho semelhante foi realizado por Manresa et al. mas este foi realizado em cães da raça beagle por até 8 semanas após a instalação. Os valores de BIC\% obtidos na análise histológica foram comparados com os valores de ISQ obtidos na RFA. Segundo os autores, não houve correlação estatisticamente significante entre o BIC\% e os valores de ISQ (45).

Para Chong et al. o macro-desenho do implante é um dos parâmetros para se alcançar a estabilidade primária. Os autores realizaram um estudo para avaliar os efeitos do desenho com lâminas auto perfurantes na estabilidade primária de implantes cônicos (tapered implants). Os implantes foram instalados em blocos de poliuretano com diferentes densidades simulando o tecido ósseo com as mesmas condições. Foram usados implantes com e sem lâminas auto-perfurantes, os implantes foram instalados com três diferentes profundidades: só o terço apical, metade do implante e a totalidade do implante. A RFA foi avaliada para analisar a estabilidade de cada implante nas diferentes situações. Concluíram que o desenho do implante como um todo e não apenas o terço apical é importante para a estabilidade primária. $\mathrm{O}$ implante sem lâminas auto perfurantes, quando totalmente 
inserido demonstrou a maior estabilidade primária inicial. O estudo demostrou ainda que a profundidade de inserção e a densidade óssea apresentaram mais forte associação com a estabilidade primária do que o macro - desenho do implante. Desta forma, quantidade óssea adequada e alta densidade podem compensar desenhos inadequados de implantes (46).

Noventa implantes foram colocados em costelas bovinas, sendo 30 implantes Bone Level, 30 Standard Plus e 30 Tapered Effect, todos da marca Straumann (Basiléia, Suíça) Estes foram avaliados com o Osstell e o Periotest. Todos os implantes apresentaram-se mecanicamente estáveis pelos métodos utilizados, mas a mais alta estabilidade foi conseguida com o implante Tapered Effect, devido ao seu macro - desenho cilíndrico/cônico (27). Outro estudo onde implantes novamente foram colocados em blocos de osso bovino e avaliados quanto a sua estabilidade primária também analisou a influência da geometria dos implantes, no entanto incluiu a análise do efeito da perda óssea marginal por meio de blocos acrílicos que iam sendo desgastados para simular o efeito da perda óssea. Os efeitos predominantes que influenciaram a estabilidade dos implantes foram a qualidade óssea e o nível de inserção. O tipo de implante e seu comprimento apresentaram alguma influência sobre os valores de estabilidade; já o diâmetro do implante apresentou pouco efeito sobre a estabilidade. Portanto, a estabilidade primária dos implantes depende de fatores como a qualidade óssea e a macro - geometria do implante (47).

Em um estudo laboratorial Karl et al. avaliaram a estabilidade primária de três marcas/modelos de implantes em modelos de poliuretano. Concluíram que o desenho do implante parece exercer um papel relevante na obtenção da estabilidade primária, especialmente em situações desafiadoras, como na colocação imediata de implantes após a exodontia (48).

\subsection{A superfície hidrofílica}

A literatura tem sugerido que implantes cuja superfície apresenta propriedades hidrofílicas demonstraram redução no tempo de osseointegração e aumento da previsibilidade do tratamento (26). Após a inserção do implante uma 
cascata de eventos biológicos inicia-se. Primeiro ocorre a osseocondução, a qual implica no recrutamento e migração de células osteogênicas para a superfície do implante, então toma lugar a formação de osso novo, resultando na formação de matriz mineralizada estável, a qual provê rigidez ao sistema e permite o carregamento mecânico do implante (28). As reações que ocorrem envolvem o coágulo sanguíneo e o implante em uma fina camada de proteína sérica, a qual evolui para tecido de granulação seguido por tecido ósseo imaturo. A formação óssea começa nas fases iniciais, durante a primeira semana, pela diferenciação de osteoblastos, produção de fatores osteogênicos, citocinas e fatores de crescimento. O osso primário que inclui o tecido ósseo trabecular é substituído por osso de fibra paralela elou osso lamelar e medular. Entre 1 e 2 semanas o tecido ósseo responsável pela estabilidade mecânica primária do implante, localizado junto ao implante, é substituído por osso novo $(5,29)$. Análises da expressão de genes durante a osseointegração e a regeneração óssea demonstraram que esses processos biológicos são complexos e envolvem uma interação de múltiplos mecanismos incluindo inflamação, angiogênese e osteogênese. Esse processo todo é influenciado pelas modificações da superfície do implante, tais como as superfícies do tipo SAE e SAE modificada para aumento da molhabilidade (10).

Superfícies moderadamente rugosas, como a SAE (SLA, Straumann), demonstram um melhor contato osso-implante (BIC) que superfícies mais antigas como a TPS (titanium plasma-sprayed), ou as jateadas com óxido de alumínio ou, ainda, as superfícies mais antigas, como as usinadas (49). Estudos in vitro comprovaram que a superfície SAE modificada é capaz de modular a função de células importantes no processo cicatricial do osso, plaquetas, células mesenquimais indiferenciadas, osteoblastos, macrófagos e células dendríticas (10). Modificações químicas, tal como a verificada nas superfície hidrofílicas (SLActive Straumann, Basiléia, Suíça), podem otimizar ainda mais o processo de osseointegração (49). Dependendo da energia superficial o implante pode ter uma superfície hidrofílica ou hidrofóbica. Quando a carga da superfície do implante é positiva, devido à baixa concentração de carbono e o consequente aumento da concentração de oxigênio, a sua superfície se torna hidrofílica e as proteínas do plasma essenciais para estabelecer os processos de osteogênese têm melhor aderência (5). As plaquetas, por serem componentes proeminentes no sangue, são as primeiras células a chegar aos implantes instalados, estas liberam proteínas com 
efeitos sob o processo cicatricial. Aumentando a complexidade da topografia da superfície dos implantes de titânio (tratamento de superfície) aumenta - se a ativação e ligação das plaquetas ao implante (10) .

Em um estudo in vitro foi avaliado efeito das alterações químicas na superfície do implante na liberação de proteínas de origem plaquetária. As superfícies de titânio com nanotopografia e hidrofilicidade aumentam a ativação plaquetária, podendo ser este o mecanismo responsável pela mais rápida osseointegração observada clinicamente com os implantes do tipo SAE modificados (SLActive) (10). As superfícies hidrofílicas têm a capacidade de tornar a absorção de proteínas mais homogênea e devido ao grande número de trombócitos ativados (plaquetas) e a uma rede espessa e homogênea de fibrina nos estágios iniciais da osseointegração permitem que esta ocorra mais rapidamente (25).

Hayashi et al. decidiram investigar as causas do BIC não ser total ou completo (100\%). O estudo avaliou os efeitos biológicos negativos da deposição de hidrocarbonetos sobre a superfície do titânio, o que foi reportado como algo inevitável. Células osteogênicas MC3T3-E1 foram cultivadas sobre discos de titânio nos quais a concentração de carbono foi experimentalmente regulada para atingir as razões de carbono/titânio $(\mathrm{C} / \mathrm{Ti})$ de $0.3,0.7$ e 1.0. As atividades celulares iniciais, tais como ligação e crescimento celular, foram suprimidas conforme a concentração do carbono aumentava sobre a superfície do titânio. As funções dos osteoblastos como atividade da fosfatase alcalina e a mineralização foram reduzidas em mais de $40 \%$ sobre a superfície $\mathrm{C} / \mathrm{Ti}$ com razão de 1.0. Esses resultados indicam que a atividade dos osteoblastos é influenciada pelo grau de contaminação da superfície do titânio por hidrocarbonetos, e a decomposição deste antes da instalação do implante pode aumentar a biocompatibilidade do titânio (15).

Como já mencionado, a topografia, a composição química, a carga elétrica e a molhabilidade afetam a absorção de proteínas, a interação celular com a superfície e o desenvolvimento celular e tecidual entre implante e hospedeiro. A elevação da molhabilidade se deve a modificação química da superfície e é dependente da baixa ou inexistente energia superficial. Esta afeta o grau de contato do implante com o ambiente fisiológico ao redor. A superfície SAE modificada (SLActive - Straumann AG, Basiléia, Suíça) foi desenvolvida com base na topografia da superfície $S A E$ (SLA - sandblasted, large-grit, acid-etched - Straumann AG, Basiléia, Suíça). É uma superfície quimicamente ativa, com baixa energia superficial, com reduzida 
contaminação atmosférica por hidrocarbonetos, alta hidroficilidade, com ângulo de contato com a água igual a $0^{\circ}$ (para SAE convencional o valor é $\left.139^{\circ}\right)$. A modificação da superfície é caracterizada pela hidroxilização e hidratação do filme de $\mathrm{TiO}_{2}$, realizado sob condições de $\mathrm{N}_{2}$, e mantido com baixa energia superficial graças ao armazenamento em solução salina isotônica (13).

Foram realizados estudos para comparar a osseointegração com vários tratamentos de superfícies de implantes, sendo a maioria em animais e poucos estudos em humanos. Lang et al. avaliaram a velocidade da osseointegração em duas superfícies diferentes (SLA e SLActive - Straumann, Suíça) durante as fases iniciais em humanos. Quarenta e nove implantes de titânio com $4 \mathrm{~mm}$ de comprimento e $2,8 \mathrm{~mm}$ de diâmetro com superfície SAE e SAE modificada (SLA e SLActive - Straumann - Suíça) foram colocados na região retro molar de 28 voluntários saudáveis. Após períodos de osseointegração submersa de 7, 14, 28 e 42 dias, os implantes foram removidos com uma broca trefina que permitiu remover o implante e mais $1 \mathrm{~mm}$ de osso ao redor. Foram feitas análises histométricas do osso novo, osso antigo, detritos ósseos, tecidos moles e o BIC. Os autores concluíram que, embora as características dos eventos de reabsorção e aposição óssea entre os 2 tipos de tratamento de superfície entre 7 e 42 dias tenham sido muito similares, o grau de osseointegração após 2 a 4 semanas foi superior para a superfície SAE modificada quando comparada com a SAE convencional (49). (Figura 2.2)

Com os mesmos espécimes e sujeitos de pesquisa de Lang et al. (49), descrito acima, Bosshardt et al. realizaram a avaliação morfológica e morfométrica da sequência de reparação e os eventos ligados à osseointegração de implantes com superfície moderadamente rugosa (SAE - SLA - Straumann) e a mesma superfície quimicamente modificada (SAE modificada - SLActive - Straumann). Os autores enfatizaram a avaliação no papel dos detritos ósseos na formação óssea. A metodologia foi a mesma empregada no estudo descrito acima, e por meio de avaliação histológica foram determinados a fração de osso nativo (OBIC), de osso novo (NBIC), de tecido mole (ST) e de detritos ósseos (BD) em contato com o implante. Todos os implantes analisados tiveram suas superfícies parcialmente cobertas com detritos ósseos e osso novo já foi observado com 7 dias após a instalação. Houve um gradual aumento do osso novo ao mesmo tempo que um decréscimo do osso nativo, tecidos moles e detritos ósseos. A fração de osso novo 
foi maior para a superfície SAE modificada do que para a SAE após 2 e 4 semanas, embora esse resultado não seja estatisticamente significante (11).

Zöllner et al. publicaram resultados preliminares de um estudo multicêntrico, prospectivo e randomizado que se propôs a avaliar as taxas de sobrevida e perda óssea marginal de implantes do tipo SAE modificado para aumento da molhabilidade (Slactive, Straumann, Suíça) instalados com carga imediata ou precoce. Selecionaram pacientes com necessidade de implantes em regiões da maxila e mandíbula posterior. Após a instalação dos implantes os pacientes receberam próteses provisórias (unitárias ou pequenas fixas) no pós cirúrgico imediato (Grupo Carga Imediata) ou após 28 a 34 dias da cirurgia (Grupo Carga Precoce). O total de 266 pacientes receberam 383 implantes (197 Grupo Carga Imediata e 186 Grupo Carga Precoce). Após 5 meses da cirurgia a taxa de sobrevida foi de $98 \%$ para o grupo Carga Imediata (Cl) e 97\% para o grupo Carga Precoce (CP)). A perda óssea marginal média foi de $0,81 \pm 0,89 \mathrm{~mm}$ para o Grupo $\mathrm{Cl}$ e de $0,56 \pm 0.73 \mathrm{~mm}$ para o Grupo CP. Segundo os autores o implante SAE modificado pode ser usado em protocolos de carga com tempo crítico (carga imediata ou precoce) quando corretos critérios de seleção dos casos são empregados. A perda óssea marginal encontrada foi considerada fisiológica, observada na literatura, e clinicamente insignificante (13).

Figura 2.2 - Porcentagem de osso novo ao redor de implantes SAE (SLA) e SAE modificado (SLActive) em semanas (49)

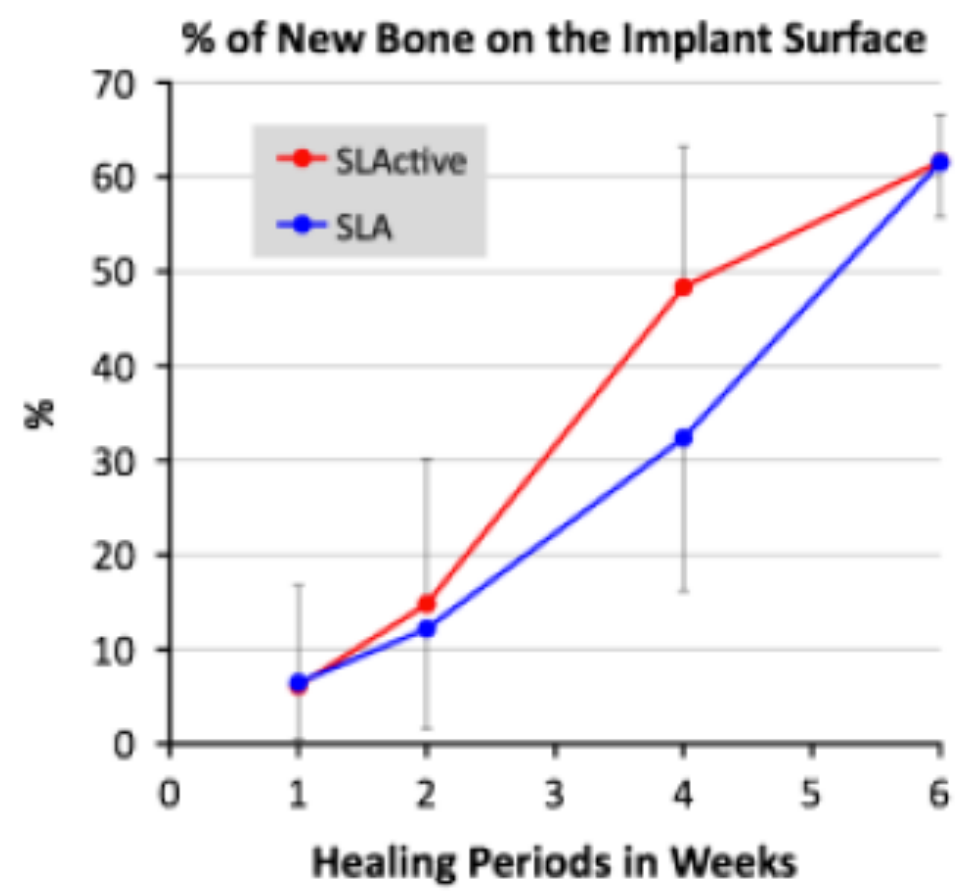


Para avaliar se a carga precoce (até 21 dias após instalação dos implantes) é segura e confiável para a prática clínica diária em implantes com superfície hidrofílica, foi realizado um estudo onde foram instalados implantes em humanos em região de osso classe I e II, já reparado, nativo e com protocolo de estágio único (implantes não submersos). O carregamento foi feito após 21 dias da inserção e os pacientes foram acompanhados clínica e radiograficamente por um ano. Vinte e um pacientes receberam 23 implantes (Element Rc Inicell, Thommen Medical AG, Grenchen, $\mathrm{CH}$ ). $\mathrm{O}$ carregamento dentro de 21 dias de implantes com superfície hidrofílica mostrou ser uma opção segura e previsível de tratamento (25).

Um estudo comparou implantes com superfície do tipo SAE (Neoporos, jateado com partículas abrasivas e por um processo de ataque ácido, Neodent, Curitiba, Brasil ) e SAE quimicamente modificada (Acqua, tratado da mesma forma que o primeiro, mas mantido em solução isotônica de cloreto de sódio a $0.9 \%$, Neodent, Curitiba, Brasil). A rugosidade dos implantes, a topografia, a composição química e a análise do ângulo de contato foram avaliadas por microscopia eletrônica, por scanner a laser, espectroscópico e pela técnica da gota séssil. Para a avaliação in vivo foram utilizados coelhos, os quais receberam 10 implantes SAE (Neoporos) nas tíbias direitas e mais 10 implantes SAE modificado (Acqua) nas tíbias esquerdas. Após 14 ou 28 dias os animais foram sacrificados e um espécime do osso da tíbia contendo o implante mais $5 \mathrm{~mm}$ de osso de cada lado foi removido. Para o grupo que utilizou a superfície SAE foi encontrado 3 vezes mais carbono na superfície que o grupo com SAE modificado, onde a concentração de oxigênio foi bem maior. A hidrofilicidade foi marcadamente superior no grupo SAE modificado embora a rugosidade entre os grupos tenham sido semelhante. Os níveis de BIC (bone-implant-contact) e BAFO (bone area fraction occupied) no grupo SAE modificado (Acqua) em 14 dias foram similares ao encontrado no grupo SAE (Neoporos) com 28 dias. Após 28 dias, as medidas de BIC e BAFO do grupo Acqua foram aproximadamente 1,5 vezes maiores que do grupo Neoporos. Os implantes com a superfície quimicamente modificada e com maior molhabilidade (Acqua) tiveram a osseointegração mais acelerada e com aumento da área de contato entre implante e osso quando comparado com implantes de superfície apenas rugosa (Neoporos) (5). 
Com o objetivo de avaliar a sobrevida e desfechos clínicos e radiográficos de implantes com superfície SAE (SLA - Straumann) e SAE modificado (SLActive Straumann) em protocolos envolvendo carga imediata e precoce, Chambrone et al. realizaram uma revisão sistemática. Os autores não encontraram diferenças significativas nos estudos analisados com relação a perda de implante ou parâmetros clínicos entre carga imediata e precoce ou protocolos tardios. Em geral, 95\% dos implantes com superfície SAE e $97 \%$ dos implantes com superfície SAE modificada sobreviveram até o final do acompanhamento (12).

A biocompatibilidade é um fator crítico na integração osso/implante e é dependente das propriedades físico-químicas da superfície do titânio (topografia, molhabilidade e composição química) (15). A molhabilidade da superfície de implantes combinada com outras características, como micro e nano topografia, energia superficial, carga elétrica e grupos funcionais determinam a cascata de eventos biológicos que ocorre na interface implante / hospedeiro. A molhabilidade é controlada pelas características da superfície do implante, tais como, a composição química da superfície e a sua topografia. Uma das formas de medir a molhabilidade é a técnica da gota séssil, que mede o ângulo de contato, o qual traduz em graus a molhabilidade de uma determinada superfície para um líquido específico. $O$ ângulo de contato pode variar de $0^{\circ}$ a $180^{\circ}$ para a água em uma superfície. $O$ ângulo inferior a $90^{\circ}$ designa a superfície como hidrofílica e acima de $90^{\circ}$ como hidrofóbica. Acima de $150^{\circ}$ a superfície é considerada super-hidrofóbica. A rugosidade da superfície é o fator que mais influi na sua hidrofilia. Superfícies hidrofilicas podem facilitar a interação inicial entre a superfície e o líquido ao redor, o que é relevante para a cicatrização e osseointegração. A rugosidade da superfície tem papel importante no comportamento da molhabilidade, e portanto na osseointegração $(50,51)$. (Figura 2.3) 
Figura 2.3 - Representação esquemática da relação do ângulo de contato com a molhabilidade (50)

\begin{tabular}{|c|c|c|c|}
\hline $\begin{array}{l}\text { Energetic } \\
\text { relationship }\end{array}$ & $\begin{array}{l}\text { CA } \\
\text { relationship }\end{array}$ & $\begin{array}{l}\text { Optical } \\
\text { representation }\end{array}$ & $\begin{array}{c}\text { Macroscopic } \\
\text { result }\end{array}$ \\
\hline$\gamma_{s v}-\gamma_{s i}>0$ & $0^{\circ} \leq \theta \leq 90^{\circ}$ & & High wettability \\
\hline$\gamma_{\mathrm{sv}}-\gamma_{\mathrm{si}}>\gamma_{\mathrm{iv}}$ & $\theta=0^{\circ}$ & & $\begin{array}{l}\text { Complete wetting } \\
\text { (spreading) }\end{array}$ \\
\hline$\gamma_{s v}-\gamma_{s l}<0$ & $90^{\circ} \leq \theta \leq 180^{\circ}$ & & Low wettability \\
\hline$\gamma_{\mathrm{sl}}-\gamma_{\mathrm{sv}}>\gamma_{\mathrm{lv}}$ & $\theta=180^{\circ}$ & & Non-wetting \\
\hline
\end{tabular}

O titânio absorve impurezas orgânicas, como hidrocarbonetos da atmosfera, da água ou de soluções. E existe um correlação entre a absorção de hidrocarbonetos pela superfície do titânio e a redução da hidrofilia, pois o ângulo de contato com a água aumenta com o aumento da absorção de hidrocarbonetos. $O$ oxigênio da superfície do titânio proveniente do $\mathrm{O}_{2}$ do ar, o qual aumenta a hidrofilicidade da superfície, é coberto por uma máscara de hidrocarbonetos absorvidos, recobrindo o dióxido de titânio ocorre a diminuição da molhabilidade. Esta última é determinada pela presença de grupos hidroxila $(\mathrm{OH})$ na superfície, com o aumento deste grupo $(\mathrm{OH})$ aumenta-se a molhabilidade e a absorção da proteína de adesão celular. A atividade do grupo hidroxila exerce influência na carga elétrica da superfície e esta tem papel importante na imobilização de moléculas tais como a proteína de adesão celular. Da mesma forma que a molhabilidade, os grupos $\mathrm{OH}$ são inibidos pela máscara de hidrocarbonetos, resultando na redução da capacidade biológica do titânio e o aumento do ângulo de contato. Alguns métodos 
são citados na literatura para a remoção do hidrocarboneto presente na superfície do titânio, tratamento com ultra-violeta, irradiação com raios gama, estocagem em solução salina fisiológica. Esses métodos podem e devem ser utilizados, mas um método ideal para a melhoria da reatividade química da superfície do titânio ainda precisa ser desenvolvido objetivando a melhor osseointegração (15).

Implantes com superfície hidrofílica e topografia obtida por jateamento de areia e ataque ácido (SAE modificado) (SLActive) demostraram melhorar a resposta osteogênica, a aposição óssea e a estabilidade durante as fases iniciais da cicatrização, quando comparados com implantes com a mesma topografia de superfície (SAE(SLA)). Os implantes SLA (Straumann) e SLActive (Straumann) são produzidos com a mesma liga de titânio e o mesmo processo para criar a rugosidade de superfície. A única diferença é que o implante com superfície hidrofílica é produzido e embalado sob condições de $\mathrm{N}_{2}$ em frascos contendo solução isotônica de $\mathrm{NaCl}$, protegendo a reatividade química do $\mathrm{TiO}_{2}$. A exposição do implante ao ar reduz a molhabilidade do $\mathrm{TiO}_{2}$ limpo, em face da absorção espontânea de hidrocarbonetos e $\mathrm{CO}_{2}$, os quais afetam a absorção inicial de proteínas pelas células de adesão. Embora a superfície de $\mathrm{TiO} 2$ seja hidrofóbica, a presença da vacância de oxigênio atômico (sobre superfície quimicamente limpa), permite a dissociação da água e a formação de grupos $\mathrm{Ti}-\mathrm{OH}$, expressando um caráter hidrofílico sob hidratação(29, 52).

Zinelis et al. realizaram um estudo com o objetivo de investigar e comparar a composição química da superfície, a capacidade de reidratação, topografia e a rugosidade de implantes Slactive e SLA (Straumann). Implantes com a mesma dimensão mas com superfície Slactive ou SLA foram submetidos a diversos testes incluindo análise química da superfície, microscopia eletrônica, capacidade de hidratação, profilometria óptica 3D, entre outros. Os autores concluíram que a superfície SLActive apresentou uma contaminação por Carbono menor que os implantes SLA, mas não significativamente diferente. Os implantes com superfície SLActive demostraram mais titânio hidroxilizado do que óxido de titânio. Os implantes com superfície SLActive apresentaram em sua superfície altas taxas de Oxigênio, $\mathrm{Na}$ e $\mathrm{Cl}$. A superfície SLActive demostrou maior capacidade de reidratação que a SLA (52).

Sartoretto et al. publicaram um estudo pré-clínico com o objetivo de comparar histologicamente e histomorfometricamente implantes com superfície SAE e SAE 
modificado (mantido em solução isotônica de cloreto de sódio a 0,9\%) nos estágios iniciais da osseointegração. Foi realizada a avaliação morfológica, topográfica e química das superfícies. Foi realizada também a avaliação da molhabilidade. Um implante de cada grupo foi instalado na tíbia esquerda de 20 ovelhas. Foram analisados os dados do BIC (bone-to-implant contact e o BA (bone area) em 7, 14, 21 e 28 dias após a instalação. Embora a morfologia e rugosidade dos implantes fosse a mesma, o grupo dos implantes com superfície SAE modificada apresentou 2,3 vezes menos carbono, o que proporcionou uma significativa melhora da molhabilidade deste grupo em relação ao com superfície SAE, além disso, também houve uma melhora dos resultados do BA e BIC em 14, 21 e 28 dias de cicatrização. Os dados sugerem que a hidroficilidade do grupo com superfície SAE modificada acelera a aposição óssea (BA) e o valores de BIC ao redor dos implantes SAE modificados durante os estágios iniciais da formação óssea, provendo um alto grau de osseointegração (14).

Com o objetivo de investigar as fases iniciais da osseointegração de implantes com superfície hidrofílica em comparação com implantes de superfície convencional hidrofóbica Vasak et al. realizaram um estudo com 9 fêmeas de mini porco (Goettingen Minipig), cada animal recebeu 12 implantes, sendo que cada quadrante recebeu um implante de cada grupo testado. Os grupos de implantes foram com superfície convencional, com superfície ativada por solução diluída de hidróxido de sódio e o terceiro grupo também com superfície hidrofílica mas mantida com solução salina (SLActive, Straumann). Os implantes foram avaliados histomorfometricamente com 5 e 15 dias após a instalação. Os autores concluíram que uma substancial aposição óssea ocorreu entre $\circ 5^{\circ}$ e $\circ 10^{\circ}$ dia e que a superfície hidrofílica pode provocar um ligeiro aumento da aposição óssea em 15 dias para os minipigs. A comparação entre os 2 tipos de superfície hidrofílica mostrou resultados irrelevantes no curto período estudado (29).

Rocuzzo \& Wilson realizaram um estudo clínico prospectivo com a proposta de avaliar se implantes com superfície hidrofílica podem ser carregados 3 semanas após a instalação. Trinta e cinco pacientes receberam um implante cada na região de molares e a estabilidade primária foi sempre obtida. Após 3 semanas da cirurgia todos os implantes receberam um provisório em oclusão, o acompanhamento foi clínico e radiográfico por um ano e nenhum implante foi perdido. Os autores 
concluíram que implantes com superfície hidrofílica podem ser carregados com três semanas em região de molares (53).

Segundo Wennerbeg et al. o implante com superfície denominada de superhidrofílica existe comercialmente, destes o mais documentado e estudado é o implante com a superfície Slactive da Straumann (Straumann, Basel, Suíça). Esta superfície é obtida pelo jateamento da superfície do titânio com partículas grandes de Corundum e o ataque com uma mistura de $\mathrm{HCl}$ e $\mathrm{H}_{2} \mathrm{SO}_{4}$. Após essa etapa a superfície do implante é enxaguada com água sob a proteção do nitrogênio e embalado com solução aquosa de $\mathrm{NaCl}$. Esta superfície está associada ao aumento da produção pelas células ósseas de fosfatase alcalina, osteoprotegerina e osteocalcina (54). Os autores realizaram um estudo para investigar como a nanoestrutura e a molhabilidade influenciam a osseointegração, e se um desses fatores ou a combinação dos dois exercem papel fundamental na melhoria da osseointegração. Para tanto utilizaram discos de titânio com 4 tipos diferentes de superfície. Uma SAE (SLA), outra SAE com nanoestrutura (SLAnano), e superfícies hidrofílicas com nanoestrutura de baixa densidade (pmodSLA) e com alta densidade (SLactive), todos com a mesma composição química e micro-rugosidade. Esses discos foram avaliados nos aspectos físico-químicos e 2 discos foram colocados em cada tíbia de 26 coelhos. Após 4 e 8 semanas foram realizados testes de força de remoção. As superfícies SLA e SLAnano foram avaliadas como hidrofóbicas e as superfícies SLActive e pmodSLA como superhidrofílicas. As primeiras apresentaram altos níveis de contaminação por carbono quando comparadas com as superhidrofílicas. Após 4 semanas a superfície SLActive apresentou a mais alta força necessária para a remoção quando comparada com as hidrofóbicas. Após 8 semanas o mesmo foi evidenciado. Os autores concluíram que uma resposta óssea mais forte é alcançada com a combinação de alta molhabilidade e a presença de nanoestrutura (SLActive) (54).

Guler et al. realizaram um estudo com 208 implantes Straumann (Basel, Suiça) onde foi avaliada a estabilidade por meio da RFA (Ostell). Do total de implantes, 164 eram SAE (SLA) e 44 eram SAE modificada (SLActive). O objetivo do estudo foi avaliar a influência de parâmetros como a região maxilar, o diâmetro do implante, o comprimento do implante e a superfície do implante nos valores de ISQ. Foram realizadas até 3 medições com o Ostell. Segundo os autores o comprimento do implante não mostrou influência significativa nos valores de ISQ, já 
o diâmetro mostrou influência na segunda e terceira medições. O gênero do paciente influenciou apenas na segunda medição, sendo que os homens apresentaram valores de ISQ significativamente mais altos. Na comparação entre as superfícies SLA e SLActive, não houve diferença na primeira medição (inserção do implante), mas houve diferença significativa na segunda medição, com a superfície SLActive com valores significativamente mais altos. Já na terceira medição não houve diferença significativa. Os autores concluíram que os valores de ISQ podem ser afetados por vários fatores. Exceto pelo comprimento do implante, outros fatores como diâmetro, período de análise, gênero, região dos maxilares e as propriedades da superfície do titânio devem ser consideradas pelos clínicos quando indica-se a terapia com implantes (55).

Han et al. publicaram um artigo com o objetivo de avaliar longitudinalmente o desenvolvimento da estabilidade de implantes com o mesmo comprimento, mas com características de superfície diferentes e com diâmetros diferentes. Para tanto foram colocados 25 implantes em 23 pacientes parcialmente dentados. Doze implantes SAE (SLA - RN - Straumann) com diâmetro de $4,1 \mathrm{~mm}, 8$ implantes com superfície SAE modificada (SLActive - RN - Straumann) com diâmetro de $4,1 \mathrm{~mm}$ e 5 implantes SAE mas com diâmetro maior, de 4,8 mm (SLA - WN - Straumann). Os implantes foram monitorados clinicamente em 6, 8 e 12 semanas após a cirurgia e por meio da RFA (Ostell) no pós cirúrgico imediato e após 4 dias, 1, 2, 3, 4, 6, 8 e 12 semanas. As médias de valores ISQ obtidas em cada tempo entre os implantes SAE (SLA - RN), SAE com diâmetro maior (SLA - WN) e SAE modificada (SLActive RN) não alcançaram diferenças estatisticamente significantes. Os autores concluíram que as mudanças longitudinais dos valores de ISQ demonstraram quase o mesmo padrão para os 3 tipos de implante. Todos os implantes apresentaram um decréscimo dos valores de ISQ após a instalação, e o valor mais baixo foi obtido entre a 3 e 4 semanas após a cirurgia e esses valores se recuperam após 8 semanas após a cirurgia (56).

Oates et al. realizaram um estudo com o objetivo de avaliar alterações na estabilidade para implantes do tipo SAE modificados quimicamente para obtenção de maior molhabilidade e implantes do tipo SAE convencional como controle. Os autores conduziram um estudo clínico randomizado com 31 pacientes, cada paciente recebeu 2 implantes com as mesmas características físicas mas com superfícies quimicamente diferentes. A RFA foi avaliada semanalmente por 6 
semanas após a instalação dos implantes. Os resultados deste estudo fornecerem suporte para o potencial dessa modificação química da superfície SAE convencional durante o processo de osseointegração e mostraram sucesso a curto prazo nos parâmetros clínicos semelhantes aos obtidos nos implantes com superfície SAE convencional (57).

Outro estudo clínico randomizado que comparou implantes com superfície do tipo SAE e SAE modificado para aumento da molhabilidade utilizando a RFA foi o de Schätzle et al. As avaliações foram feitas no pós cirúrgico imediato e 7, 14, 21, 28, $35,42,49,56,70$ e 84 dias após a cirurgia. Com 12 semanas os implantes com a superfície SAE modificada apresentaram resultados de estabilidade significativamente maiores que o grupo de implantes com superfície SAE convencional. Os autores afirmaram que os resultados suportam o potencial da modificação química da superfície SAE influenciar positivamente o processo biológico da osseointegração e a redução do tempo necessário para que esta ocorra (58).

Rossi et al. em um estudo prospectivo com acompanhamento de 5 anos, avaliaram clinicamente, radiograficamente e por meio da RFA 40 implantes com

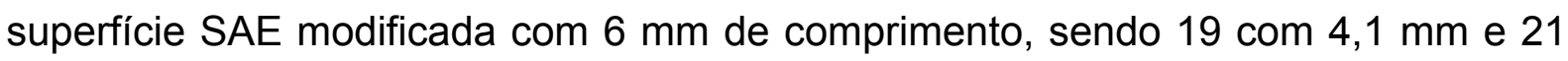
com 4,8 mm de diâmetro, respectivamente. Os autores concluíram que implantes com superfície SAE modificada e $6 \mathrm{~mm}$ de comprimento suportam coroas unitárias em região posterior quando carregados após 6 a 7 semanas da colocação, os quais se mantiveram em função por pelo menos 5 anos com pouca reabsorção óssea marginal (59).

Segundo Hicklin et al. pesquisadores passaram a focar na química das superfícies dos implantes como um outro fator chave para a aposição óssea ao redor dos implantes, devido a influência exercida pelas propriedades químicas sobre a tensão superficial e a molhabilidade. A molhabilidade é altamente dependente da energia superficial e influencia o grau de contato da superfície do implante e o meio fisiológico durante as fases iniciais da osseointegração (60). Com o objetivo de avaliar a aplicação de carga em um protocolo precoce de 21 dias após a cirurgia em um implante com superfície hidrofílica, os autores instalaram implantes em paciente com a região posterior da mandíbula parcialmente desdentada. Após a cirurgia de instalação os implantes foram moldados, os valores de ISQ foram medidos após 21 dias, caso fossem $\geq 70$, o implante era restaurado com provisórios com contato 
oclusal. Os valores de ISQ foram reavaliados após 1, 3 e 6 meses. Todos os 20 implantes testados apresentaram ISQ $\geq 70$ após 21 dias, os valores de ISQ aumentaram gradativamente até os sexto mês. As avaliações clínicas mostraram a estabilidade dos tecidos e o exame radiográfico mostrou a estabilidade dos níveis ósseos marginais. Os autores concluíram que o carregamento funcional de implantes com superfície hidrofílica após 3 semanas parece ser um tratamento seguro e uma opção de tratamento para sítios cicatrizados na mandíbula posterior (60).

Markovic et al. realizaram uma pesquisa do tipo RCT comparando implantes de TiZr (Titânio Zircônio) com superfície hidrofílica e com superfície hidrofóbica em pacientes que fazem uso continuo de anticoagulantes. Um total de 80 implantes foram instalados em 20 pacientes, os implantes foram avaliados pela RFA até 0 terceiro mês pós instalação. A taxa de sobrevida e sucesso foram avaliadas por até um ano de acompanhamento. Após um ano, a taxa de sucesso e sobrevida foi de $100 \%$, uma significante queda nos valores de ISQ foi observada em comparação aos valores do pós cirúrgico imediato na primeira semana para os implantes com superfície hidrofílica (SAE modificada), o que foi notado apenas na terceira semana para o grupo de implantes com superfície hidrofóbica (SAE convencional). No entanto, não foram encontradas grandes diferenças nos valores de ISQ entre os implantes dos 2 tipos de superfície. Os autores concluíram que implantes confeccionados de TiZr de diâmetro reduzido com a superfície hidrofóbica ou hidrofílica alcançam e mantem uma adequada integração ao tecido ósseo em pacientes que utilizam anticoagulantes. Os anticoagulantes parecem exercer influência sobre a reparação óssea o que resultou em valores de ISQ mais baixos ao final dos três meses de pós operatório que os valores iniciais, mas sem comprometer a estabilidade dos implantes (61).

Donos et al. realizaram um ensaio clínico randomizado com o objetivo de determinar o impacto clínico da instalação do provisório sobre implantes do tipo bone level (nível ósseo) com superfície hidrofílica (SAE modificado). Para tanto instalaram 24 implantes unitários em 24 pacientes, os sítios implantares eram todos cicatrizados, 12 desses implantes receberam coroas provisórias sem oclusão e os outros 12 ficaram com o cicatrizador. Parâmetros clínicos, radiográficos e estéticos foram avaliados com 12 e 24 meses após a instalação. Os autores concluíram que a 
instalação dos provisórios de forma imediata é um procedimento viável para implantes unitários (62). 


\section{MATERIAIS E MÉTODOS}

Esta pesquisa foi realizada com o desenho de ensaio clínico randomizado, duplo cego e com grupos paralelos. Foi desenvolvida no Centro de Excelência em Prótese e Implante (CEPI), na Clínica Odontológica da Faculdade de Odontologia da Universidade de São Paulo. O planejamento e todas as intervenções clínicas e cirúrgicas para a colocação dos implantes, bem como a coleta dos dados foram realizados na referida clínica.

Para a seleção dos pacientes participantes da pesquisa (sujeitos de pesquisa) foram definidos critérios de inclusão e exclusão. Os de elegibilidade/inclusão foram: pacientes que apresentassem ausências dentárias na região posterior da maxila (região de pré-molares e molares), podendo ser espaço intercalar ou extremidade livre, com indicação de próteses implantossuportadas, com idade entre 25 e 65 anos, sem contraindicações sistêmicas e não fumantes, capazes de compreender e assinar um termo de consentimento livre e esclarecido (apresentado no ANEXO A), com boa higiene oral, sítios para recebimento do implante com pelo menos 3 meses de cicatrização após exodontia, adequada altura e largura óssea, permitindo a manutenção de $1 \mathrm{~mm}$ de osso por vestibular e por lingual e $3 \mathrm{~mm}$ até os dentes adjacentes, para instalação de um implante de $4,3 \mathrm{~mm}$ de diâmetro por $10 \mathrm{~mm}$ de altura (Drive Cone Morse (Neodent, Curitiba, Brasil)). (Figura 3.1) Devido a grande dificuldade em se conseguir pacientes com áreas desdentadas em maxila com tal altura, puderam ser incluídos casos com até $8 \mathrm{~mm}$ de altura mínima. Para pacientes que apresentaram vários espaços protéticos na maxila posterior, cada um deles pôde ser incluído de forma independente no estudo. 
Figura 3.1 - A - Implante Drive Neoporos e B - Implante Drive Acqua (Neodent, Curitiba, Brasil)
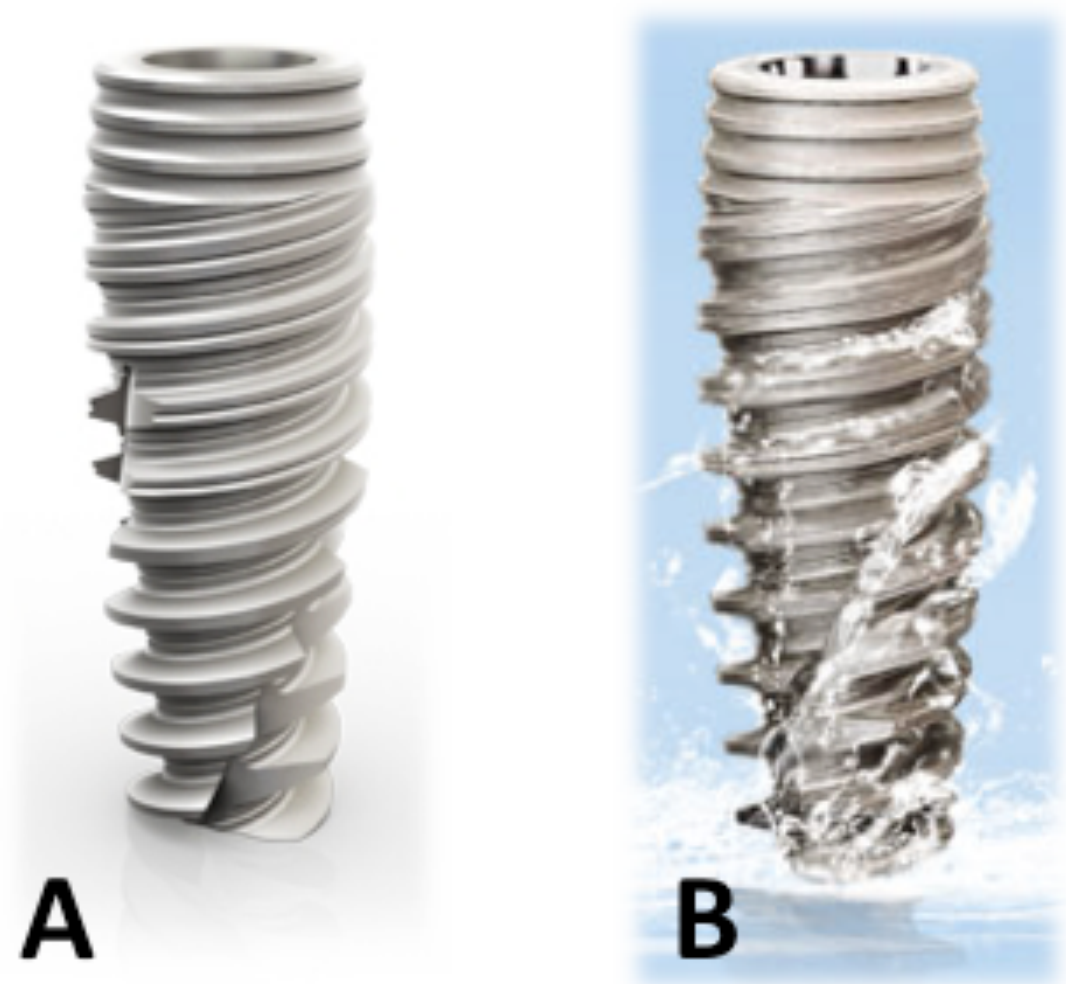

Os critérios de exclusão estabelecidos foram: pacientes que necessitavam de implantes na mandíbula ou maxila anterior (ossos tipo I e II), ou que apresentavam qualquer uma das seguintes condições: contraindicações gerais para procedimentos cirúrgicos, diabetes não controlada, severo bruxismo ou apertamento, gestantes e lactantes, doenças periodontais ativas, tabagismo, uso de álcool ou drogas e pacientes imunodeprimidos. Pacientes que realizaram radioterapia em regiões próximas à cavidade bucal, quimioterapia e os que usavam ou usaram recentemente bisfosfonatos, tais como o Alendronato.

Inicialmente os pacientes foram triados por meio de anamnese, exame clínico e avaliação da radiografia panorâmica. Para todos os pacientes a intervenção foi planejada de forma semelhante: instalação de implantes osseointegrados com a medida de 4,3 $\mathrm{mm}$ de diâmetro por $10 \mathrm{~mm}$ de comprimento em áreas desdentadas da maxila posterior. O planejamento pré - cirúrgico orientou-se pelo planejamento protético prévio o que permitiu maior previsibilidade na confecção das próteses. $A$ sequência do planejamento foi a seguinte: moldagem e obtenção de modelos de estudo, montagem em articulador semi-ajustável, análise da oclusão e avaliação da 
radiografia panorâmica. Após a confirmação da viabilidade do caso, foram confeccionados guias tomográficos em resina acrílica ou estampado com placa de acetato com marcadores radiopacos (guta percha ou lâminas de chumbo), essas guias foram confeccionadas com base em enceramentos de diagnóstico ou montagem de dentes de estoque. Os pacientes foram encaminhados a centros de radiologia para a realização de tomografia do tipo Feixe-Cônico (Cone-Beam). Com as tomografias foi possível realizar os planejamentos virtuais de cada caso no programa de computador Dental Slice (Bioparts Prototipagem, Brasília, Brasil), todos os sítios implantares receberam os implantes na melhor posição tridimensional para a confecção das próteses.

Para a cirurgia, os pacientes foram medicados com Amoxicilina $500 \mathrm{mg}$ de 8 e 8 horas por 7 dias, iniciando na noite anterior ao procedimento. Também indicouse a Nimesulida de $100 \mathrm{mg}$ de $12 \mathrm{em} 12$ horas por 4 dias, após a instalação dos implantes. Analgésicos (Paracetamol $750 \mathrm{mg}$ ) foram receitados quando necessários. Todos os cuidados com biossegurança necessários para esse tipo de cirurgia foram tomados, tais como uso de kits de cirurgia com campos, aventais e luvas estéreis. Os sujeitos de pesquisa receberam anestesia infiltrativa no local com mepivacaína. As cirurgias foram realizadas com a abertura de retalho de espessura total e a fresagem do osso conforme preconiza o fabricante para a instalação do implante Drive de 4,3 mm de diâmetro por $10 \mathrm{~mm}$ de comprimento. $\mathrm{O}$ kit cirúrgico utilizado foi o da Neodent (Curitiba, Brasil), o qual é capaz de instalar o implante supracitado. Em todos os pacientes a cirurgia foi do tipo "único estágio cirúrgico", ou seja; os implantes receberam cicatrizadores, os quais não ficaram submersos. A razão disso é a necessidade de acoplar um dispositivo chamado smartpeg type $A 3$ (Osstell $A B$, Gotemburgo, Suécia) (Figura 3.2) ao implante no momento da coleta dos dados. Para não gerar micro-movimentos no implante e atrapalhar a osseointegração a Neodent desenvolveu especialmente para esta pesquisa um cicatrizador com rosca na sua porção superior, no mesmo local do orifício hexagonal que acopla a chave de 1,2 mm. Desta forma, o Smartpeg, do tipo A3, usado sob pilares protéticos pôde ser rosqueado no cicatrizador, com a vantagem de não precisar remover este último. Sem a remoção do cicatrizador para a coleta de dados os implantes não sofreram torques precoces. Para a instalação dos cicatrizadores ao final da colocação dos implantes, estabelecemos que o torque mínimo de instalação dos implantes fosse de $10 \mathrm{~N} / \mathrm{cm}^{2}$ para que tal implante fosse incluído na pesquisa. 
Figura 3.2 - Smartpeg type A3 (A). Smartpeg type A3 acoplado ao cicatrizador especialmente desenvolvido para esta pesquisa $(B)$

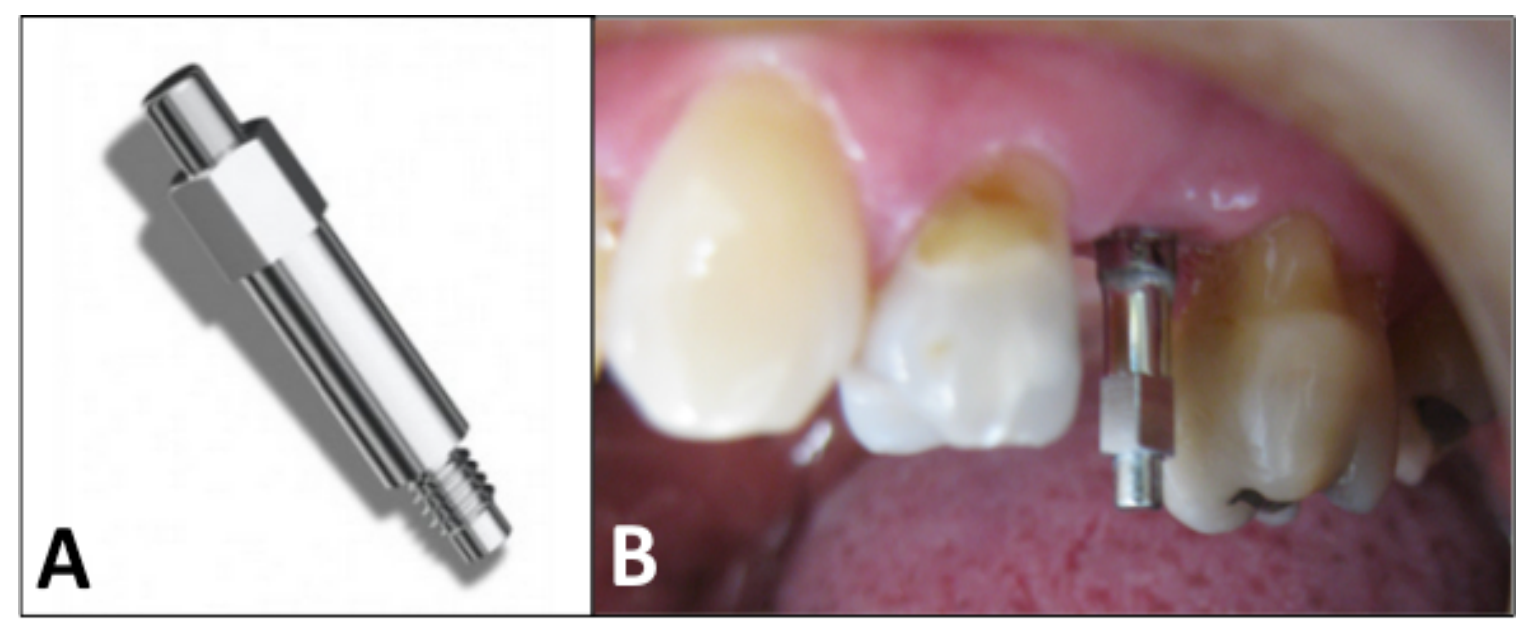

A coleta de dados foi realizada pelo período de 16 semanas, e as informações coletadas em 8 tempos. No pós cirúrgico imediato (T0), após 1 semana (T1), 2 semanas (T2), 3 semanas (T3), 5 semanas (T4), 8 semanas (T5), 12 semanas (T6) e 16 semanas (T7). A coleta foi feita por meio do Osstell e do smartpeg type A3, sempre anotando os valores de ISQ obtidos no sentido MésioDistal e depois no sentido Vestíbulo-Palatino. Com esses 2 valores para cada implante, em cada momento foi feita uma média aritmética que foi o valor utilizado para o implante no tempo correspondente (Figura 3.3) (Anexo D). 
Figura 3.3 - Obtenção de valor de ISQ no sentido vestíbulo-palatino

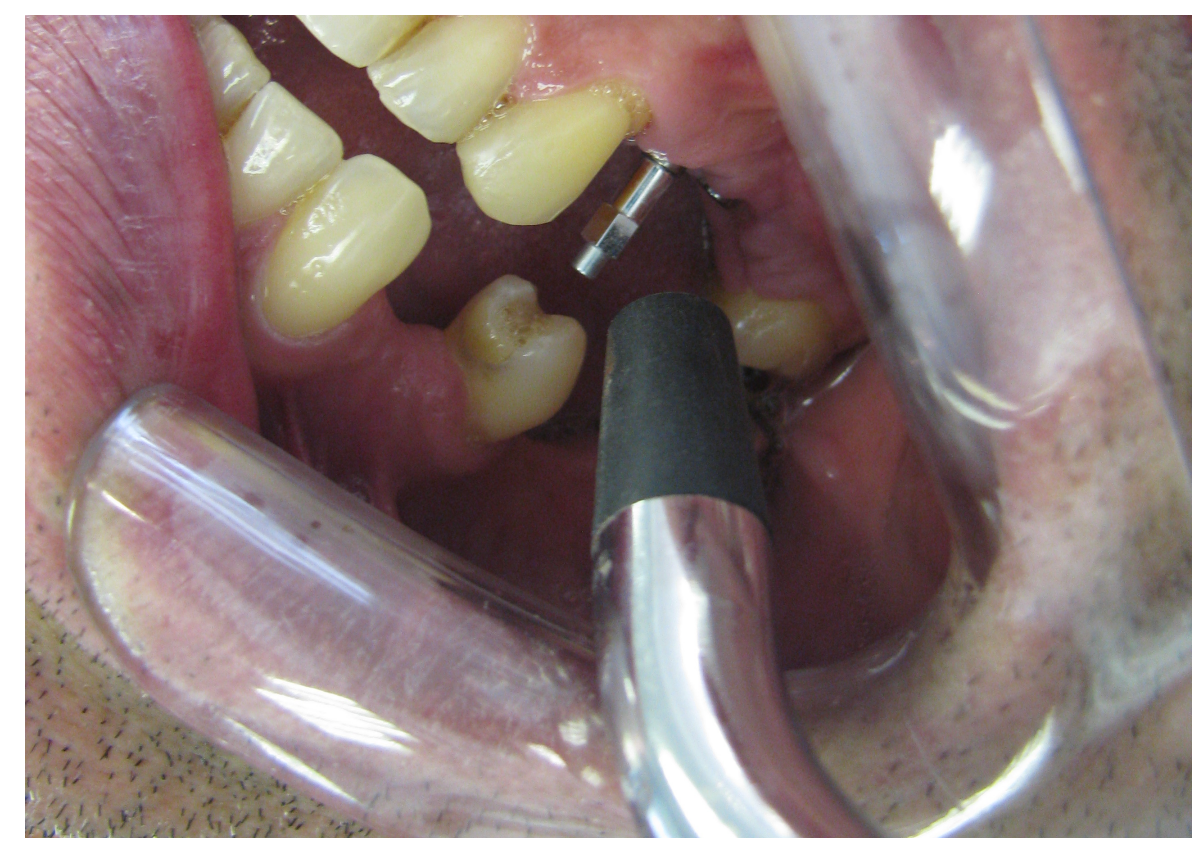

O desfecho primário foi a estabilidade dos implantes ao longo do tempo avaliado pelo dispositivo Ostell (Figura 3.4). O desfecho secundário, representou as possíveis complicações decorrentes da instalação dos implantes, como não osseointegração, infecções, edema, perda precoce. Incluímos ainda um terceiro desfecho, a sobrevida dos implantes, observada por meio da avaliação clínica e radiográfica dos implantes após pelo menos um ano da cirurgia de instalação. Com esse acompanhamento (follow-up) obteve-se além de informações no que concerne a sobrevida, mas também da manutenção dos tecidos periimplantares. Todos os pacientes foram chamados depois de pelo menos um ano da instalação dos implantes para serem submetidos a exame radiográfico (periapical) buscando determinar se houve alguma radiolucência ou perda óssea significativa que possa interferir no sucesso da reabilitação com implantes. No exame clínico os implantes foram avaliados quanto ao torque sobre o cicatrizador com chave digital ou avaliação de mobilidade nos já reabilitados, avaliação com sonda periodontal, nas intersecções das faces $V / M, V / D, P / M$ e $P / D$, para a análise de possíveis sangramento e/ou supuração (Figura 3.5). 
Figura 3.4 - Aparelho Osstell em função

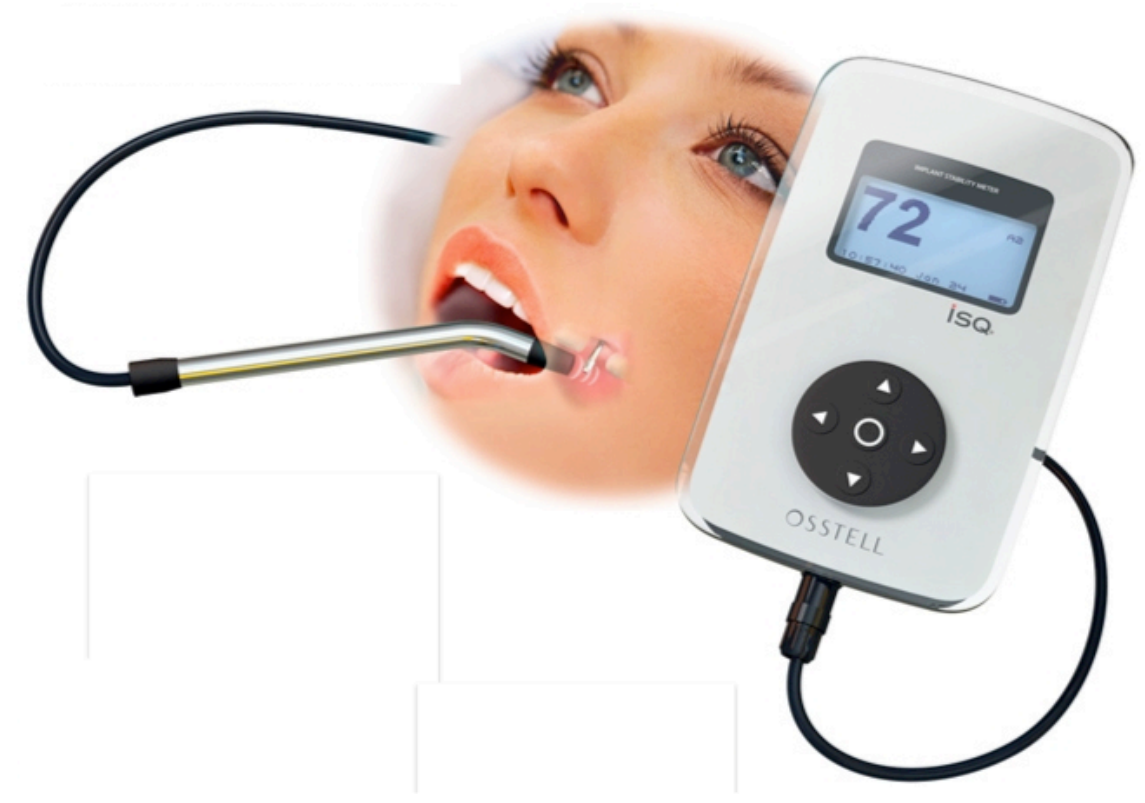

Figura 3.5 - Sondagem em exame clínico (A), exame radiográfico (B)

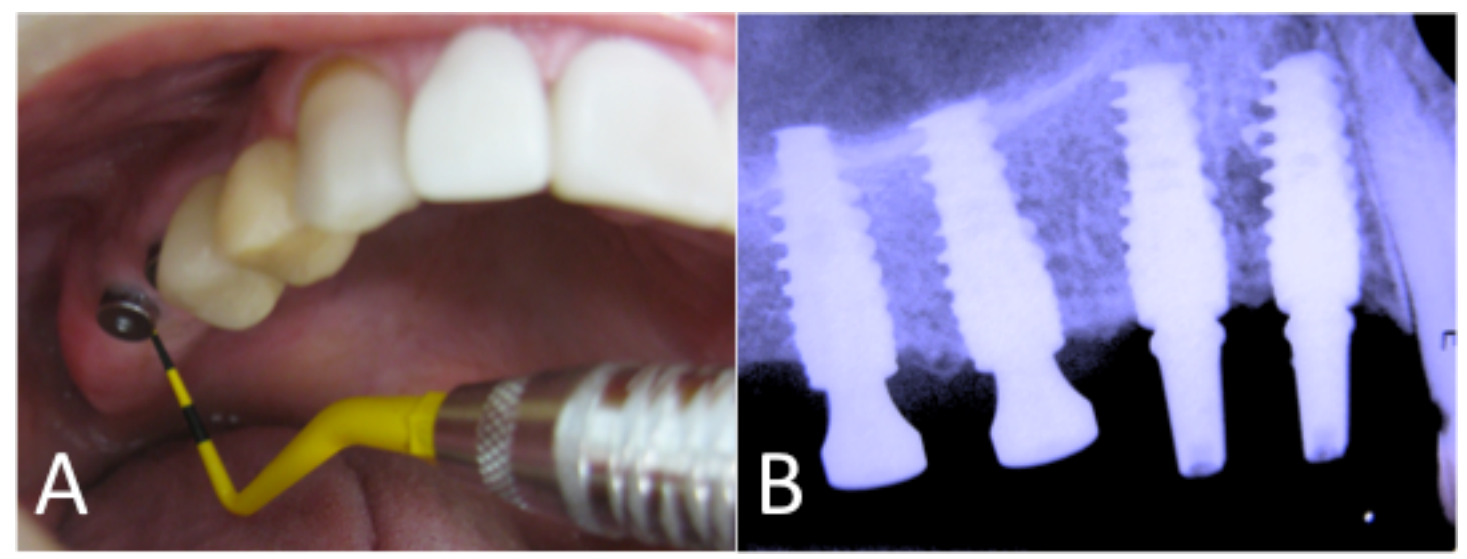

A amostra (número de implantes) foi definida por meio de projeto piloto onde se obteve o desvio padrão para a instalação de 10 implantes (5 do grupo teste e outros 5 do grupo controle). Com o dado do desvio padrão, para um nível de significância de 5\%, e poder (chance de detectar uma real diferença entre as médias) de 90\%, calculou-se por meio do site Sealed Envelope 
(www.sealedenvelope.com) o tamanho da amostra necessária. Chegou-se ao número de 64 implantes, sendo 32 em cada grupo.

Neste estudo os pacientes não foram alocados em grupos, mas sim os locais ou áreas desdentadas destes pacientes, denominados sítios implantares. Os sítios foram alocados em dois grupos, sendo um denominado Grupo Controle (C), que recebeu implantes com tratamento de superfície com jateamento de areia e duplo ataque ácido (Superfície Neoporos, Neodent, Curitiba) e outro, Grupo Teste (T), nos quais foram instalados implantes com superfície quimicamente modificada e alta molhabilidade (Superfície Acqua, Neodent, Curitiba). Com essa metodologia, onde os sítios implantares foram randomizados, 12 pacientes do total de $21(57 \%)$ receberam implantes dos dois grupos ( $\mathrm{C}$ e $\mathrm{T}$ ). Isso foi vantajoso, pois reduziu o risco de viés da pesquisa, já que o mesmo paciente, com as mesmas características ósseas e sistêmicas tiveram implantes diferentes, dos Grupos C e T, instalados.

A randomização foi realizada por meio do site Research Randomizer (https://www.randomizer.org) em um único bloco com 64 números, conhecida como randomização simples, com razão de alocação de 1:1, semelhante ao "cara coroa" realizado com moeda. Esse tipo de randomização, embora mais simples, apresenta o menor risco de viés e, como afirma Moher et al., é uma forma mais elegantemente sofisticada de randomização pois é mais imprevisível e supera os níveis de prevenção de viés de outras alternativas de randomização (21). Os sítios foram incluídos conforme a sequência de chegada dos pacientes à triagem e em correspondência aos números de 1 a 64 do bloco único de randomização. $\mathrm{Na}$ situação do paciente ter mais de um sítio implantar (área desdentada) a sequência seguida para correspondência com o bloco de randomização foi sempre do quadrante 1 para o 2 e seguindo a ordem numérica dos elementos dentais, ou seja, do dente 14 ao dente 27 . O site de randomização forneceu sequências numéricas para cada número do bloco de randomização (1 a 64), quando o número randomizado era par, este determinou a alocação do sítio implantar para o grupo Controle, já quando o número indicado era ímpar o sítio implantar foi alocado no grupo Teste. Apenas para controle da planilha, os sítios implantares receberam um número indicando a ordem de chegada (sequência) dos pacientes e a ordem do sítio dentro da boca (de 14 a 27). Por exemplo: sítio implantar 3.2, o primeiro número mostra a ordem de chegada do paciente, ou seja, terceiro paciente triado e incluso. 
Já o segundo número indica a ordem crescente da região dentro da boca (sempre obedecendo a sequência de 14 a 27), ou seja, o segundo sítio implantar incluso.

Apenas o cirurgião e seu auxiliar souberam a qual grupo o sítio implantar pertence, Controle ou Teste, já que, estes não poderão ser cegados, pois os implantes apresentam características físicas macroscópicas diferentes, o Neoporos é seco e o Acqua vem imerso em solução salina isotônica. Já os pacientes e o pesquisador que fez a coleta dos dados desconheciam completamente a alocação dos sítios implantares e o tipo de implantes instalados em cada um desses sítios. (Tabela 3.1)

Tabela 3.1 - Exemplo da randomização e sequência de entrada dos sujeitos de pesquisa. A sequência da região em uma mesma boca seguiu a ordem de 14 a 27 . A randomização obedeceu a ordem de entrada (chegada) do sujeito de pesquisa e a sequência numérica (1 a 10) e a alocação nos grupos dependeu se o número randomizado foi par ou ímpar. Os nomes apresentados são fictícios

\begin{tabular}{|lllccl|}
$\begin{array}{c}\text { Ordem de } \\
\text { chegada }\end{array}$ & $\begin{array}{c}\text { Nome do } \\
\text { Paciente }\end{array}$ & $\begin{array}{c}\text { Sequência da } \\
\text { região na } \\
\text { boca (14 a 27) }\end{array}$ & $\begin{array}{c}\text { Sequência da } \\
\text { randomização }\end{array}$ & $\begin{array}{c}\text { Número } \\
\text { randomizado } \\
\text { (site) }\end{array}$ & $\begin{array}{c}\text { Par (Controle) ou } \\
\text { Ímpar (Teste) }\end{array}$ \\
\hline 1 & Antonio & $14(1.1)$ & 1 & 3 & Teste (acqua) \\
\hline & Antonio & $16(1.2)$ & 2 & 7 & Teste (acqua) \\
\hline $\mathbf{2}$ & José & $25(2.1)$ & 3 & 6 & Controle (Neoporos) \\
\hline 3 & Maria & $17(3.1)$ & 4 & 2 & Controle (Neoporos) \\
\hline & Maria & $26(3.2)$ & 5 & 1 & Teste (acqua) \\
\hline 4 & João & $15(4.1)$ & 6 & 9 & Teste (acqua) \\
\hline & João & $16(4.2)$ & 7 & 10 & Controle (Neoporos) \\
\hline & João & $17(4.3)$ & 8 & 4 & Controle (Neoporos) \\
\hline 5 & Carlos & $26(5.1)$ & 9 & 5 & Teste (acqua) \\
\hline 6 & Joana & $14(6.1)$ & 10 & 8 & Controle (Neoporos) \\
\hline
\end{tabular}

A análise estatística utilizada para comparar os grupos foi o ANOVA de medidas repetidas, para o a análise do fator de interação foi realizado o teste de Greenhouse- Geisser. Em complementação ao teste ANOVA, foram utilizados os dados do intervalo de confiança para verificar em qual momento houve a diferença entre os grupos, era fundamental saber o ponto onde os grupos se diferenciaram, isto ficou muito claro no gráfico 4.1. Um gráfico do tipo Kaplan-Meier demostrou o survival rate de acordo com o tempo. Este gráfico não tem relação com a sobrevida dos implantes, mas sim com o número de implantes que alcançaram um 
determinado valor de acordo com o tempo, apenas foi utilizado um gráfico de taxa de sobrevida. Para esse teste especificamente o valor de corte foi determinado com o objetivo de comparar a variação do ISQ de ambas as curvas e não como um fator determinante da osseointegração. $O$ teste foi realizado para avaliar o desempenho do tratamento de superfície e não com a função de avaliar a perda ou falhas dos implantes.

O resultado do teste do Survival mostrou como os implantes foram alcançando o ISQ $\geq 70$ para cada tempo. A regressão de Cox foi realizada para avaliar o tempo necessário para que os grupos atingissem o ISQ $\geq 70$. Da mesma forma, a Hazard Ratio (HR) foi usada para comparar o "risco" dos implantes atingirem o ISQ $\geq 70$.

Como em todo ensaio clínico, foi necessária a obtenção da aprovação do Comitê de Ética em Pesquisa (CEP) anteriormente ao início do desenvolvimento do estudo. A pesquisa foi apresentada ao Comitê de Ética em Pesquisa da FOUSP por meio da Plataforma Brasil (CONEP), juntamente com termo de consentimento livre e esclarecido (TCLE) especialmente produzido para este estudo, obtendo a sua aprovação (CAAE 18911913.7.0000.0075) como consta no Anexo B.

Os estudos clínicos aleatórios, conhecidos como RCTs (Randomized Clinical Trials) em inglês, seguem diretrizes definidas pelo CONSORT STATEMENT (21), o qual preconiza entre outras coisas o registro do projeto de pesquisa em sítios públicos da Internet. Esse tipo de registro possibilita que a comunidade científica acompanhe $\mathrm{o}$ trabalho dando ao mesmo a transparência e credibilidade aos resultados obtidos. O presente estudo foi registrado na fase de projeto no sítio Clinical Trials (http://clinicaltrials.gov). Após o correto registro este sítio emite a confirmação do mesmo e um número de controle. O identificador obtido foi NCT02134743 e o registro completo se encontra no Anexo C. 


\section{RESULTADOS}

\subsection{Dados populacionais}

Para a instalação de 64 implantes, 32 para cada grupo (Teste e Controle), conforme indicou o cálculo da amostra, foram recrutados 21 pacientes com ausências dentárias na maxila posterior. Destes sujeitos de pesquisa, 8 eram homens e 13 mulheres, sendo a amostra composta de 38,095\% de homens e $61,905 \%$ de mulheres. A média de idade foi de $49 \pm 3,6$ anos, sendo o mais jovem com idade de 27 anos e o mais velho com 64 anos. As cirurgias e o processo de cicatrização transcorreu sem complicações, com um baixo nível de desconforto pósoperatório para todo grupo de pacientes. Durante a avaliação da RFA (16 semanas) não houve drop out, ou seja, todos os implantes foram avaliados dentro dos tempos pré-determinados para a avaliação da estabilidade.

O torque médio avaliado no momento da instalação dos implantes foi de $35,125 \pm 4,498$. O torque médio para o grupo Teste (SAE modificado -Superfície Acqua) foi de $34,656 \pm 6,940$ e para o grupo Controle (SAE convencional Superfície Neoporos) foi de 36,063 $\pm 5,995$.

\subsection{Avaliação da estabilidade}

Para o grupo Controle, os valores mínimos e máximos durante todo o estudo foram de 42 e 81 respectivamente e para o grupo Teste os valores foram 32,5 e 82,5 respectivamente. O gráfico 4.1 mostra a média e intervalo de confiança para cada grupo semana a semana. A partir da quinta semana o grupo Teste apresentou valores superiores aos do grupo controle, que se manteve dessa forma até o final do estudo. 
Gráfico 4.1 - Média dos valores de ISQ e intervalo de confiança para o grupo Controle e Teste semana a semana

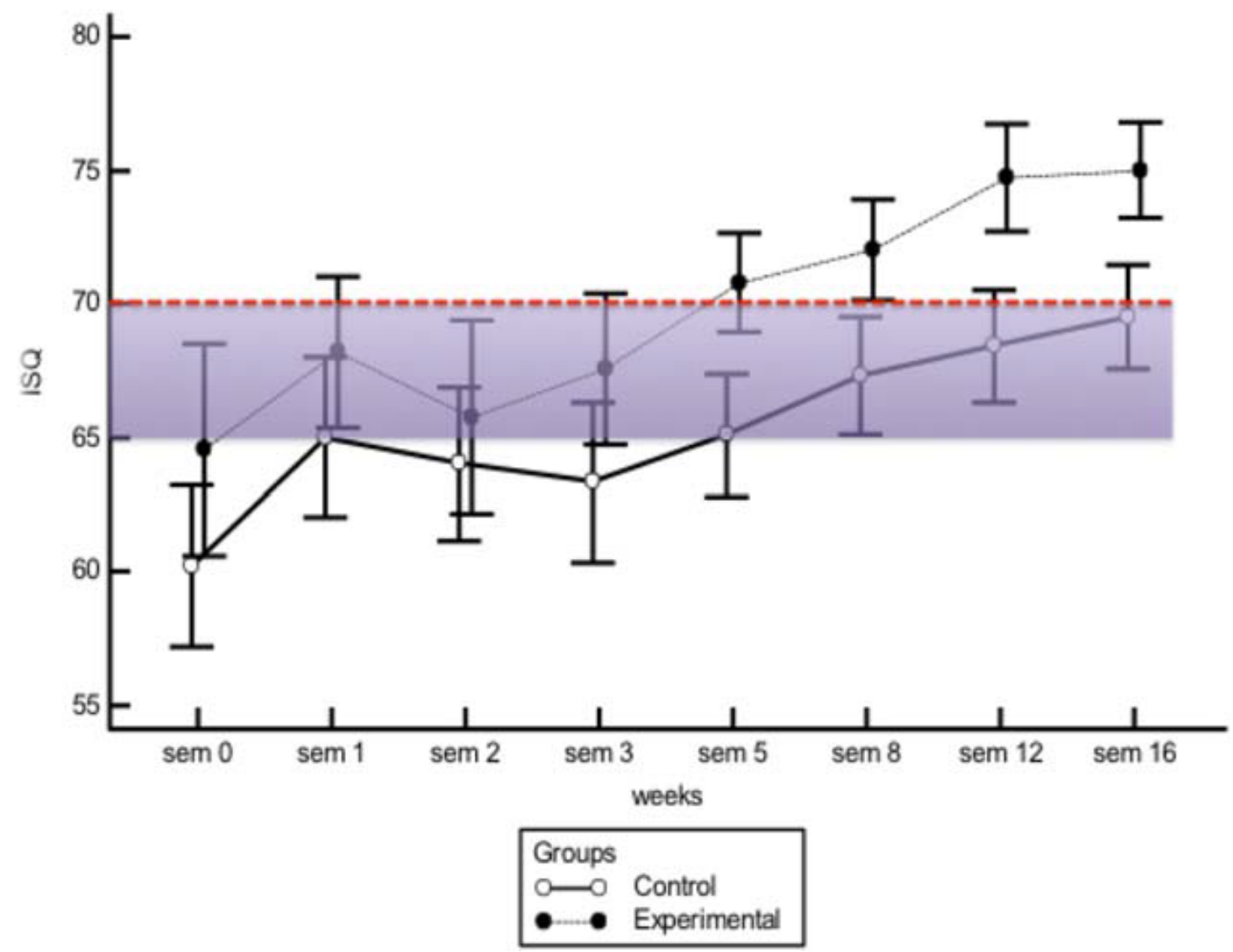

$\mathrm{Na}$ comparação pelo método de ANOVA de medidas repetidas, houve diferença estatisticamente significante $(p<0,01)$ quando comparados os grupos (Teste Vs. Controle). Na comparação entre o fator de interação (semanas) também houve diferença estatisticamente significante para ambos os grupos $(p<0,01)$. Fator esse mostrado pelo Gráfico 4.1 onde pode-se observar o aumento do valor de ISQ de acordo com o período decorrido. Na comparação grupo Vs. fator de interação não houve diferença estatisticamente significante pela análise de Greenhouse-Geisser $(p=0,150)$, mostrando que as duas curvas se comportam de maneira semelhante (valor de ISQ ascendente em relação ao tempo).

Para a avaliação do Survival Rate, foi estipulado como desfecho o sucesso da estabilidade do implante, ou seja um ISQ $\geq 70$. O gráfico de Kaplan-Meier está representado na gráfico 4.2 . 
Gráfico 4.2 - Gráfico de Kaplan-Meier para grupo teste e controle, com o desfecho sendo sucesso da estabilidade do implante (ISQ $\geq 70$ )

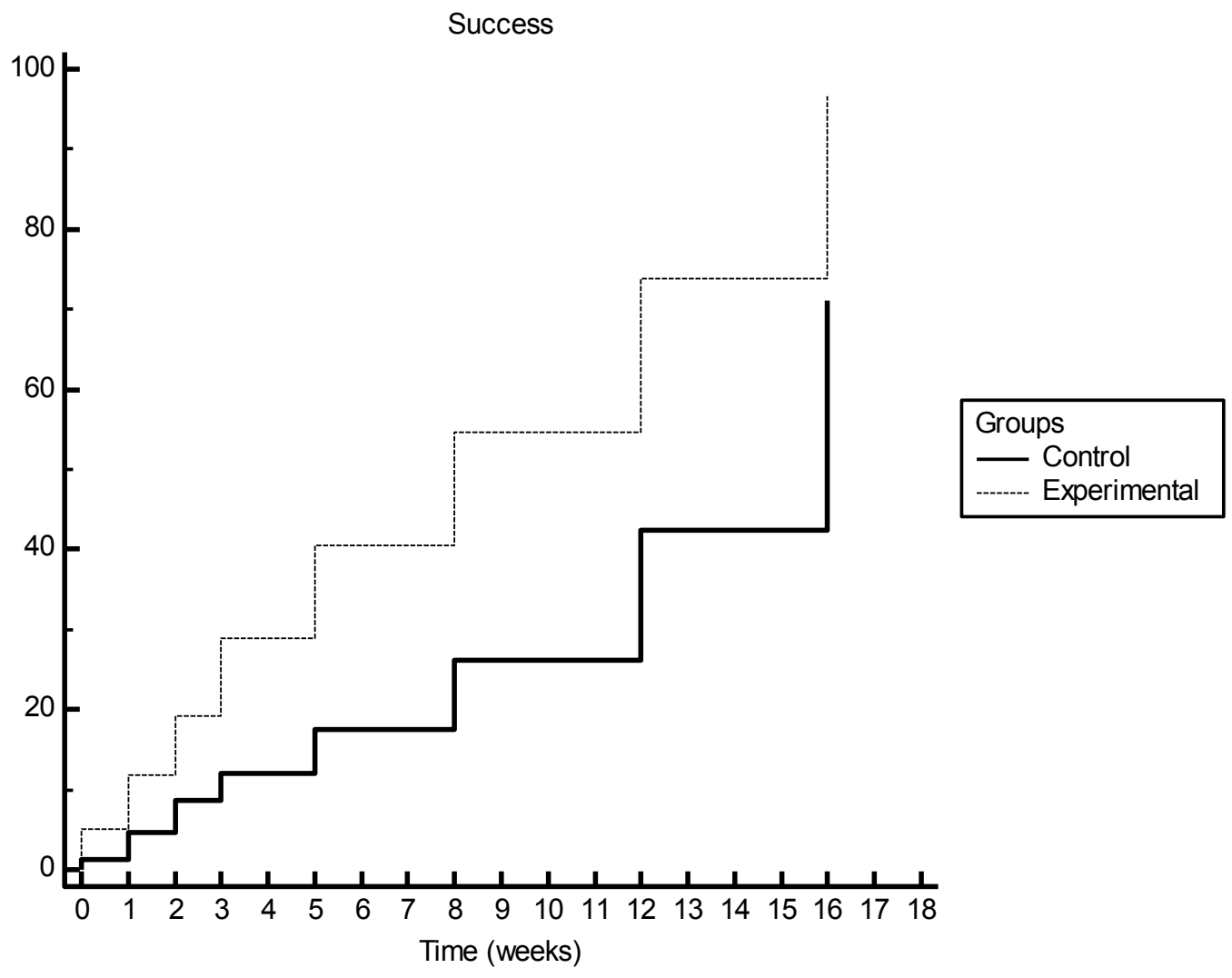

De acordo com a regressão de Cox, para a comparação entre os grupos com relação ao tempo necessário para se atingir o sucesso (ISQ $\geq 70)$, houve diferença estatisticamente significante $(p<0,01)$, e um Hazard Ratio $(H R)$ de 2,24 (Cl 1,62$3,11)$. Dessa forma o grupo Teste não só apresentou diferença estatisticamente significante quando comparado com o grupo Controle para os casos onde o ISQ fosse $\geq 70$, como para esse grupo o tempo necessário para isso acontecer foi 2,24 vezes mais rápido do que o grupo controle.

O valor de ISQ $\geq 70$ foi determinado como desfecho baseado nas próprias recomendações da fabricante do Ostell (Figura 1, Página 15) e na literatura, Hicklin et al. (2015) só instalaram provisórios nos implantes cujo ISQ fosse $\geq 70$ após 21 dias da instalação (60). 


\subsection{Acompanhamento de um ano}

$\mathrm{Na}$ avaliação do acompanhamento após um ano da cirurgia para colocação dos implantes, dos 21 pacientes que receberam 64 implantes apenas um não apresentou-se no retorno, portanto tivemos um drop out de um paciente com 2 implantes instalados. No momento da avaliação, dos 62 implantes avaliados, 29 $(46,77 \%)$ ainda não haviam sido reabilitados. Nenhum apresentou mobilidade, dor quando aplicado torque no cicatrizador nos não reabilitados e dor a percussão nos reabilitados. Apenas $7(11,29 \%)$ apresentaram sangramento à sondagem mas nenhum apresentou supuração. Apenas um $(1,61 \%)$ apresentou perda óssea mais significativa em exame radiográfico em virtude da desadaptação da coroa realizada. 


\section{DISCUSSÃO}

Para essa pesquisa foram selecionados 21 pacientes, desse total 12 receberam implantes de ambos os grupos ( $\mathrm{C}$ e $\mathrm{T}$ ). Embora não houvesse a intenção de fazer um estudo do tipo boca dividida e como os implantes e não os pacientes foram randomizados e alocados nos respectivos grupos, criou-se uma situação na qual implantes diferentes (grupo C e T) foram colocados no mesmo paciente, com suas características biológicas próprias, condições sistêmicas e hábitos. Essa característica da randomização, embora não seja um estudo de boca dividida propriamente dito, reduziu o risco de viés da pesquisa.

De um total de 64 implantes, 40 foram instalados em pacientes do sexo feminino e 24 em pacientes dos sexo masculino. Dos 40 implantes instalados em mulheres, 20 foram alocados no grupo $\mathrm{C}$ e 20 no grupo T. O mesmo ocorreu com relação aos homens, ou seja, 12 por grupo. Essa configuração ocorreu graças ao trabalho da coincidência, mas permitiu uma redução do viés, ao dividir os grupos de forma mais equilibrada. Segundo Guller et al. o gênero interfere com os valores de $I S Q$, sendo que homens tendem a apresentar valores mais altos (55). Já para Ostman et al. as diferenças na análise com a RFA entre os gêneros não são clinicamente significantes e que não há diferenças entre os índices de falha (perda) entre homens e mulheres (40). Para Guler et al. os resultados da estabilidade de implantes durante o processo da osseointegração é diferente entre homens e mulheres, mas no final do processo os clínicos não devem levar em consideração o gênero do paciente (55). Em virtude do que foi encontrado na literatura e a possibilidade de haver implantes dos dois grupos na mesma boca foi decidido não realizar uma análise estatística específica das diferenças entre os gêneros.

Outros fatores também podem influenciar a estabilidade dos implantes: diâmetro, comprimento, geometria e região podem afetar os valores de ISQ. Alguns autores afirmam que não há necessidade da colocação de implantes muito longos, pois o comprimento não afetaria os valores de ISQ $(31,55)$. Sim \& Lang demostraram que o comprimento do implante tem influência sobre os valores de estabilidade (ISQ), mas que a região dos maxilares (qualidade óssea) teria maior importância para a análise com o a RFA (30). Com relação ao diâmetro não existe um consenso se este afeta a estabilidade do implante, mas o desenho do implante e 
a região da sua colocação parecem afetar os valores de ISQ $(27,30,40,47,56)$. Na presente pesquisa apenas implantes com o mesmo comprimento, diâmetro e desenho foram instalados. A região da colocação dos implantes foi sempre a mesma (maxila posterior).

Clinicamente, a tecnologia RFA pode ser muito útil para monitorar a evolução da estabilidade de um implante desde a sua instalação, durante a osseointegração e a sua fase final de cicatrização (24). Uso de medições repetidas separadas por intervalos após a instalação de um implante é considerada uma forma de determinar o momento apropriado para o seu carregamento (24), pois um aumento dos valores de ISQ com o passar do tempo podem, provavelmente, refletir a aposição óssea e o remodelamento deste na interface osso-implante $(39,56)$.

Não existe um consenso na literatura sobre a relação da RFA e a osseointegração e os valores de \%BIC. Kunnekel et al. afirmam em um estudo em animais que é possível fazer essa correlação, o mesmo afirma Park et al., pois correlaciona RFA e \%BIC e ainda diz que o primeiro permite prever o segundo (44). Já Degidi et al. concluíram que a relação estre a estrutura óssea e RFA ainda não está totalmente compreendida $(6,20)$. Manresa et al. foram mais categóricos em afirmar que não houve correlação entre \%BIC e os valores de ISQ (45).

Com relação ao tempo de 16 semanas de análise dos valores de ISQ desta pesquisa, tal período foi determinado com base no tempo normalmente utilizado nos protocolos de carregamento com critérios clínicos em osso do tipo III e IV. Além disso, metade dos implantes da pesquisa apresentava caraterísticas hidrofóbicas e portanto necessitavam de maior tempo para o carregamento. Han et al. avaliaram os implantes por 12 semanas, sendo que na sua amostra haviam implantes instalados em maxila e mandíbula (56). O mesmo tempo de análise foi usado por Schätzle et al., Van Eekeren et al., Huwller et al. e Hicklin et al. que avaliou os valores de ISQ por 6 meses $(26,42,58,60)$. Para Van Eekeren et al. mais importante do que o tempo total da análise é a frequência com que as mensurações são feitas, pois só assim é possível determinar o padrão de evolução da estabilidade dos implantes (26).

Nesta pesquisa, o valor médio máximo de ISQ durante as 16 semanas foi de 82,5 e o mínimo valor médio de ISQ foi de 32,5. O Valor máximo de ISQ está em concordância com valores encontrados em outros estudos clínicos mas o valor mínimo não está. Han et al obtiveram 84 como o valor de ISQ médio mais alto e 55 
como o valor mais baixo (56). Ersanli et al obtiveram 82 e 57 como o valor de ISQ mais alto e mais baixo, respectivamente, e um valor de ISQ médio de 69 (38). As diferenças entre a presente pesquisa e os demais estudos, talvez, esteja relacionada ao fato dos autores desses estudos terem incluído nas pesquisas implantes colocados em ambos os maxilares (maxila e mandíbula) e também porque os implantes dessas pesquisa tinham diferentes comprimentos, diâmetros e desenhos geométricos. Sim \& Lang demostraram mais baixos valores de ISQ para osso do tipo III e IV quando comparados com osso do tipo I e II $(30,64)$. No presente estudo, todos os implantes tinham o mesmo desenho geométrico e as mesmas dimensões (Drive $\mathrm{CM} 4,3 \times 10$ ) e todos foram colocados na maxila posterior.

Observando os valores médios de ISQ, no decorrer das 16 semanas, é possível notar que nesta pesquisa houve um decréscimo dos valores na segunda e terceira semanas depois da colocação do implante para os grupos Teste e Controle, respectivamente. Após esse pico de queda do valor do ISQ, a média começou a subir semana após semana. Esses resultados estão em linha com outros estudos $(38,41,42,55,56)$ e sugerem a existência de um intervalo onde a estabilidade primária cai e a secundária inicia seu aumento, ou seja, a estabilidade deixa de ser mecânica e passa a ser biológica, neste período o implante apresenta a sua menor estabilidade. Essa queda nos valores de ISQ demonstram a perda da estabilidade primária e a recuperação dos valores de ISQ o início da estabilidade secundária. Histologicamente, em estudos em animais, nas duas primeiras semanas o tecido ósseo responsável pela estabilidade primária é substituído por osso novo $(5,29)$. A osseointegração ocorre apenas após o processo de reabsorção óssea, promovendo uma queda na estabilidade mecânica por curto período de tempo (64), e uma subsequente queda nos valores do ISQ. O grupo Teste apresentou seu valor mais baixo na segunda semana e o grupo Controle na terceira semana, provavelmente porque a modificação química da superfície dos implantes do grupo Teste deve ter acelerado os eventos biológicos relacionados à osseointegração. Van Eekeren et al. encontraram resultados similares para implantes com superfície hidrofílica; como no presente estudo, a maior depressão da estabilidade foi mais alta na segunda semana (26). Ainda como esta pesquisa, outros autores demonstraram que implantes sem a superfície hidrofílica apresentaram seus pontos de estabilidade mais baixos na terceira ou quarta semana $(26,43)$. 
$\mathrm{Na}$ atual pesquisa, a partir da quinta semana a média dos valores de ISQ do grupo Teste demostraram diferenças significativas em relação aos valores do grupo Controle, os quais são demonstradas no Gráfico 4.1. A média dos valores de ISQ do grupo Teste (Superfície Acqua) manteve-se mais alta que do a média dos valores do grupo Controle, mas a partir da quinta semana com uma diferença significativa, e foi assim até o final da avaliação com dezesseis semanas. É possível argumentar que implantes com superfície SAE modificada demonstrem um ganho de estabilidade maior e mais rápido do que implantes apenas coma superfície SAE. O aumento da estabilidade, após o apropriado período de cicatrização, pode ser considerado, como descrito na literatura $(28,30,56)$, a osseointegração propriamente dita. Sim \& Lang especularam que um aumento significativo nos valores do ISQ pode representar o estabelecimento da osseointegração, a qual substitui a estabilidade primária mecânica (30).

Para ambos os grupos os valores médios de ISQ foram subindo de forma constante como foi demonstrado na comparação entre os grupos versus o fator de interação, o qual não foi estatisticamente significante (Greenhouse- Geisser), em outras palavras, a média dos valores de ISQ foram ascendendo com o tempo para os dois grupos. Pode-se especular que ao final do processo de cicatrização/ osseointegração as duas superfícies de implante poderiam demonstrar resultados similares de ISQ. Han et al demonstraram que implantes com superfície SLActive (Straumann, Suíça) (SAE modificada) apresentaram valores de ISQ mais altos que a superfície SLA (Straumann, Suíça) (SAE) no inicio e no meio do estudo, mas no final da pesquisa não há diferença significativa entre as duas superfícies. Levando a crer que a superfície SLActive (hidrofílica) poderia ser mais adequada para o carregamento precoce. Após 3 meses a análise com a RFA não apresentou diferenças estatisticamente significativas entre as superfícies SLActive e SLA (56). Lang et al avaliaram o BIC (bone to implant contact) de implantes com superfície SAE e SAE modificada em humanos no período de 7 a 42 dias. Os implantes com a superfícies SAE modificada foram superiores em relação aos valores de BIC depois de 14 e 28 dias mas ao final de 42 dias, os valores de BIC foram iguais e altamente satisfatórios para ambas as superfícies (49).

Nesta pesquisa os implantes utilizados tinham a mesma superfície utilizada nas pesquisas realizadas por Sartoretto et al. $(5,14)$, esta superfície apresenta propriedades baseadas em um fenômeno físico-químico, que é a mudança na 
eletronegatividade do óxido de titânio e a subsequente armazenagem do implante em solução salina, convertendo a mesma em uma superfície mais hidrofílica e com maior energia superficial livre. A carga da superfície e a molhabilidade somadas à topografia, são fatores que podem melhorar a osseointegração dos implantes de titânio (14).

O mais rápido e maior ganho de estabilidade pode ser muito importante para o uso do protocolo de carga precoce, pois o aumento da estabilidade pode ser traduzido em uma maior e mais rápida osseointegração. Assim como Lang et al outros autores conduziram estudos histológicos, no entanto em modelos animais ( 5 , 29). Sartoretto et al., em um estudo que avaliou a molhabilidade além de outras propriedades das superfícies de implantes, pesquisou o BIC e o BAFO (bone area fraction occupied) de duas diferentes superfícies de implantes instalados em tíbias de coelhos. Implantes com superfície modificada para o aumento da molhabilidade demonstraram em 14 dias BIC e BAFO similares aos de implantes sem a modificação mas após 28 dias da instalação (5), em outras palavras, a superfície modificada para maior molhabilidade apresentou uma osseointegração 2 vezes mais rápida. Estudos clínicos também confirmam a possibilidade do uso de protocolos de carga precoce para implantes com superfícies SAE modificadas. Bornstein et al. verificaram em um estudo clinico retrospectivo que implantes com superfície SLActive (hidrofilica) (Straumann) podem ser carregados com 3 semanas ao invés de 6 ou 8 (4). Roccuzzo et al. confirmaram que o sucesso do carregamento funcional de implantes com superfície quimicamente modificada é possível com 3 semanas na região de molares maxilares (53).

Neste estudo não foi possível afirmar que implantes com superfície SAE modificada tiveram uma maior ou melhor osseointegração, apenas que essa ocorreu de forma mais rápida. $\mathrm{O}$ mais rápido ganho de estabilidade observado nos implantes do grupo Teste, observados pela tecnologia RFA, podem apontar um aumento do percentual do $B I C(B I C \%)$. Park et al. mostraram significativa correlação entre valores de ISQ medidos com a tecnologia RFA e o percentual de BIC (BIC\%) em tíbias de coelhos após 4 semanas de cicatrização (44). Manresa et al., no entanto, em um estudo com cães, não encontraram correlação entre os valores de ISQ (determinados por RFA) e o percentual de BIC obtidos por análise histomorfométrica (45). A qualidade da conexão entre o osso e o implante deve ser analisada em diversos fatores, como o $\mathrm{BIC} \%$, a densidade óssea e o comprimento efetivo do 
implante. Contudo, esses parâmetros só podem ser estudados por análises histológicas, as quais são naturalmente invasivas (26).

Para este estudo foi determinado o valor de ISQ $\geq 70$ para avaliar a taxa de sucesso pois este valor é considerado o objetivo de sucesso para a estabilidade do implante. No sítio eletrônico do fabricante do dispositivo Ostell está descriminado que valores de ISQ $\geq 70$ é considerado um valor de alta estabilidade, entre 60-69 é um valor de média estabilidade e ISQ < 60 é apontado com um valor de baixa estabilidade (17). Hicklin et al. só restauraram com coroas provisórias os implantes que após 21 dias de instalação apresentassem ISQ $\geq 70$, ou seja, estabeleceram esse valor de ISQ como sendo um desfecho de sucesso. O Gráfico 4.2 aponta o total de implantes que alcançaram o valor de ISQ $\geq 70$ durante as 16 semanas. Esse número foi mais alto para o grupo Teste em relação ao grupo Controle, sendo que ao final de 16 semanas quase $100 \%$ dos implantes do grupo Teste alcançaram ISQ $\geq 70$ e apenas pouco mais que $70 \%$ do grupo Controle tiveram o mesmo resultado. Como demonstrado pela análise estatística, o grupo $\mathrm{T}$ foi 2,24 vezes mais rápido em alcançar o valor de ISQ considerado sucesso $(\geq 70)$ que o grupo C. Este resultado está em concordância com outros estudos, que realizaram análises histomorfométricas, clínicas e/ou avaliações com a tecnologia RFA (4, 5, 49, 53, 57, $58)$.

No acompanhamento de um ano do estudo, 62 do total de 64 implantes foram avaliados. Todos estavam osseointegrados. Nenhum paciente apresentou dor sob teste de percussão ou à aplicação de torque no cicatrizador. Apenas 7 tiveram sangramento à sondagem e apenas um implante apresentou perda óssea detectável em exame radiográfico. Estes resultados estão em linha com outros estudos que apresentaram implantes com superfície SAE e SAE modificada com mais de $95 \%$ de taxa de sobrevida $(4,53,57,59)$. A perda óssea detectável do implante mencionado acima se deveu a uma restauração com pobre adaptação, portanto não foi uma falha relativa ao implante, mas sim uma falha protética.

Embora muito venha sendo estudado sobre o assunto, mais estudos clínicos randomizados $(R C T)$ são necessários para a verificação científica dos resultados já descritos na literatura. Roccuzzo et al. afirmaram que mais RCTs são essenciais para a confirmação da hipótese que os implantes com superfície $S A E$ modificada acelerem a osseointegração e reduzam as falhas nas fases iniciais da reparação (53). Chambrone et al., em uma revisão sistemática, concluíram que poucos RCTs 
sobre implantes com superfície SLActive estão disponíveis para análise. E para os autores não há evidências suficientes para suportar ou refutar diferenças significativas entre implantes com superfície SLA e SLActive. Os poucos estudos selecionados demostraram uma ampla variedade de protocolos de carregamento, tornando difícil apresentar uma conclusão definitiva. Eles, finalmente, concluem afirmando a necessidade de novos estudos prospectivos com longos prazos de avaliação (12). 


\section{CONCLUSÃO}

Os resultados do presente estudo, embora com as limitações próprias da análise com a tecnologia RFA, sugerem que implantes com superfície hidrofilica podem osseointegrar mais rápido que implantes com superfície SAE convencional. O ganho de estabilidade do grupo Teste foi 2,24 vezes mais rápido que o do grupo Controle e um maior número de implantes do grupo $T$ alcançaram o sucesso determinado (ISQ $\geq 70$ ) em 16 semanas. Os implantes de ambos os grupos apresentaram uma sobrevida de $100 \%$ após um ano. Novas pesquisas sobre implantes com superfície $S A E$ modificada, especialmente $R C T$ s, são necessárias. 


\section{REFERÊNCIAS ${ }^{1}$}

1. Zwaan J, Vanden Bogaerde L, Sahlin H, Sennerby L. A One-year Follow-up Study of a Tapered Hydrophilic Implant Design Using Various Placement Protocols in the Maxilla. Open Dent J. 2016 Dec 9;10:680-691. doi: 10.2174/1874210601610010680..

2. Laney WR. In recognition of an implant pioneer: Professor Dr. Andre Schroeder. Int J Oral Maxillofac Implants. 1993;8(2):135-6.

3. Babbush CA. Titanium plasma spray screw implant system for reconstruction of the edentulous mandible. Dent Clin North Am. 1986 Jan;30(1):117-31.

4. Bornstein MM, Wittneben JG, Bragger U, Buser D. Early loading at 21 days of non-submerged titanium implants with a chemically modified sandblasted and acidetched surface: 3 -year results of a prospective study in the posterior mandible. J Periodontol. 2010;81(6):809-18.

5. Sartoretto SC, Alves AT, Resende RF, Calasans-Maia J, Granjeiro JM, Calasans-Maia MD. Early osseointegration driven by the surface chemistry and wettability of dental implants. J Appl Oral Sci. 2015 May-Jun;23(3):279-87. doi: 10.1590/1678-775720140483.

6. Degidi M, Piattelli A, Shibli JA, Perrotti V, lezzi G. Bone formation around onestage implants with a modified sandblasted and acid-etched surface: human histologic results at 4 weeks. Int J Periodontics Restorative Dent. 2009;29(6):607-13.

7. Vasak C, Busenlechner D, Schwarze UY, Leitner HF, Munoz Guzon F, Hefti T, et al. Early bone apposition to hydrophilic and hydrophobic titanium implant surfaces: a histologic and histomorphometric study in minipigs. Clin Oral Implants Res. 2014;25(12):1378-85.

8. Al-Nawas BH, U.; Duschner, H.; Krummenauer, F.; Wagner, W. Turned, machined versus double-etched dental implants in vivo. Clin Implant Dent Relat Res. 2007;9(2):71-8.

\footnotetext{
${ }^{1}$ De acordo com o Estilo Vancouver.
} 
9. Felice P, Pistilli R, Piattelli M, Soardi E, Corvino V, Esposito M. Posterior atrophic jaws rehabilitated with prostheses supported by $5 \times 5 \mathrm{~mm}$ implants with a novel nanostructured calcium-incorporated titanium surface or by longer implants in augmented bone. Preliminary results from a randomised controlled trial. Eur J Oral Implantol. 2012 Summer;5(2):149-61.

10. Alfarsi MA, Hamlet SM, Ivanovski S. Titanium surface hydrophilicity enhances platelet activation. Dent Mater J. 2014;33(6):749-56. Epub 2014 Oct 11.

11. Bosshardt DD, Salvi GE, Huynh-Ba G, Ivanovski S, Donos N, Lang NP. The role of bone debris in early healing adjacent to hydrophilic and hydrophobic implant surfaces in man. Clin Oral Implants Res. 2011;22(4):357-64.

12. Chambrone L, Shibli JA, Mercúrio CE, Cardoso B, Preshaw PM. Efficacy of standard (SLA) and modified sandblasted and acid-etched (SLActive) dental implants in promoting immediate and/or early occlusal loading protocols: a systematic review of prospective studies. Clin Oral Implants Res. 2015 Apr;26(4):359-70. doi: 10.1111/clr.12347. Epub 2014 Feb 21. Review.

13. Zollner A, Ganeles J, Korostoff J, Guerra F, Krafft T, Bragger U. Immediate and early non-occlusal loading of Straumann implants with a chemically modified surface (SLActive) in the posterior mandible and maxilla: interim results from a prospective multicenter randomized-controlled study. Clin Oral Implants Res. 2008;19(5):442-50.

14. Sartoretto SC, Alves AT, Zarranz L, Jorge MZ, Granjeiro JM, Calasans-Maia MD. Hydrophilic surface of Ti6Al4V-ELI alloy improves the early bone apposition of sheep tibia. Clin Oral Implants Res. 2016.

15. Hayashi R, Ueno T, Migita S, Tsutsumi Y, Doi H, Ogawa T, et al. Hydrocarbon Deposition Attenuates Osteoblast Activity on Titanium. J Dent Res. 2014;93(7):698703.

16. Sennerby L, Roos J. Surgical determinants of clinical success of osseointegrated oral implants: a review of the literature. Int $\mathrm{J}$ Prosthodont. 1998;11(5):408-20.

17. Sennerby L, Meredith N. Implant stability measurements using resonance frequency analysis: biological and biomechanical aspects and clinical implications. Periodontol 2000. 2008;47:51-66. 
18. Aparicio C, Lang NP, Rangert B. Validity and clinical significance of biomechanical testing of implant/bone interface. Clin Oral Implants Res. 2006;17 Suppl 2:2-7.

19. Park JC, Kim HD, Kim SM, Kim MJ, Lee JH. A comparison of implant stability quotients measured using magnetic resonance frequency analysis from two directions: a prospective clinical study during the initial healing period. Clin Oral Implants Res. 2010;21(6):591-7.

20. Kunnekel AT, Nair KC, Naidu EM, Sivagami G. Validation of resonance frequency analysis by comparing implant stability quotient values with histomorphometric data. J Oral Implantol. 2011;37(3):301-8.

21. Moher D, Hopewell S, Schulz KF, Montori V, Gotzsche PC, Devereaux PJ, et al. CONSORT 2010 explanation and elaboration: updated guidelines for reporting parallel group randomised trials. Int J Surg. 2012;10(1):28-55.

22. Albrektsson T, Branemark PI, Hansson HA, Lindstrom J. Osseointegrated titanium implants. Requirements for ensuring a long-lasting, direct bone-to-implant anchorage in man. Acta Orthop Scand. 1981;52(2):155-70.

23. Rowan M, Lee D, Pi-Anfruns J, Shiffler P, Aghaloo T, Moy PK. Mechanical versus biological stability of immediate and delayed implant placement using resonance frequency analysis. J Oral Maxillofac Surg. 2015;73(2):253-7.

24. Atieh MA, Alsabeeha NH, Payne AG. Can resonance frequency analysis predict failure risk of immediately loaded implants? Int $\mathrm{J}$ Prosthodont. 2012;25(4):326-39.

25. Hinkle RM, Rimer SR, Morgan MH, Zeman P. Loading of titanium implants with hydrophilic endosteal surface 3 weeks after insertion: clinical and radiological outcome of a 12-month prospective clinical trial. J Oral Maxillofac Surgery. 2014;72(8):1495-502.

26. van Eekeren $P$, Said C, Tahmaseb A, Wismeijer D. Resonance Frequency Analysis of Thermal Acid-Etched, Hydrophilic Implants During First 3 Months of Healing and Osseointegration in an Early-Loading Protocol. Int $\mathrm{J}$ Oral Maxillofac Implants. 2015;30(4):843-50. 
27. Romanos GE, Ciornei G, Jucan A, Malmstrom H, Gupta B. In vitro assessment of primary stability of Straumann(R) implant designs. Clin Implant Dent Relat Res. 2014;16(1):89-95.

28. Al-Hamdan SH, Al-Hamdan K, Junker R, Jansen JA. Effect of implant surface properties on peri-implant bone healing: implant stability and microcomputed tomographic analysis. Int J Oral Maxillofac Implants. 2012;27(1):77-83.

29. Vasak C, Busenlechner D, Schwarze UY, Leitner HF, Munoz Guzon F, Hefti T, et al. Early bone apposition to hydrophilic and hydrophobic titanium implant surfaces: a histologic and histomorphometric study in minipigs. Clin Oral Implants Res. 2013.

30. Sim CP, Lang NP. Factors influencing resonance frequency analysis assessed by Osstell mentor during implant tissue integration: I. Instrument positioning, bone structure, implant length. Clin Oral Implants Res. 2010;21(6):598604.

31. Balleri P, Cozzolino A, Ghelli L, Momicchioli G, Varriale A. Stability measurements of osseointegrated implants using Osstell in partially edentulous jaws after 1 year of loading: a pilot study. Clin Implant Dent Relat Res. 2002;4(3):128-32.

32. Glauser R, Sennerby L, Meredith N, Ree A, Lundgren A, Gottlow J, et al. Resonance frequency analysis of implants subjected to immediate or early functional occlusal loading. Successful vs. failing implants. Clin Oral Implants Res. 2004;15(4):428-34.

33. Meredith N, Alleyne D, Cawley P. Quantitative determination of the stability of the implant-tissue interface using resonance frequency analysis. Clin Oral Implants Res. 1996;7(3):261-7.

34. Meredith N, Book K, Friberg B, Jemt T, Sennerby L. Resonance frequency measurements of implant stability in vivo. A cross-sectional and longitudinal study of resonance frequency measurements on implants in the edentulous and partially dentate maxilla. Clin Oral Implants Res. 1997;8(3):226-33.

35. Bornstein MM, Hart CN, Halbritter SA, Morton D, Buser D. Early loading of nonsubmerged titanium implants with a chemically modified sand-blasted and acidetched surface: 6-month results of a prospective case series study in the posterior mandible focusing on peri-implant crestal bone changes and implant stability quotient (ISQ) values. Clin Implant Dent Relat Res. 2009;11(4):338-47. 
36. Ostman PO, Hellman M, Sennerby L. Direct implant loading in the edentulous maxilla using a bone density-adapted surgical protocol and primary implant stability criteria for inclusion. Clin Implant Dent Relat Res. 2005;7 Suppl 1:S60-9.

37. Fuster-Torres MA, Penarrocha-Diago M, Penarrocha-Oltra D. Relationships between bone density values from cone beam computed tomography, maximum insertion torque, and resonance frequency analysis at implant placement: a pilot study. Int J Oral Maxillofac Implants. 2011;26(5):1051-6.

38. Ersanli S, Karabuda C, Beck F, Leblebicioglu B. Resonance frequency analysis of one-stage dental implant stability during the osseointegration period. J Periodontol. 2005;76(7):1066-71.

39. Degidi M, Perrotti V, Piattelli A, lezzi G. Mineralized bone-implant contact and implant stability quotient in 16 human implants retrieved after early healing periods: a histologic and histomorphometric evaluation. Int $\mathrm{J}$ Oral Maxillofac Implants. 2010;25(1):45-8.

40. Ostman PO, Hellman M, Wendelhag I, Sennerby L. Resonance frequency analysis measurements of implants at placement surgery. Int $\mathrm{J}$ Prosthodont. 2006;19(1):77-83; discussion 4.

41. Valderrama P, Oates TW, Jones AA, Simpson J, Schoolfield JD, Cochran DL. Evaluation of two different resonance frequency devices to detect implant stability: a clinical trial. J Periodontol. 2007;78(2):262-72.

42. Huwiler MA, Pjetursson BE, Bosshardt DD, Salvi GE, Lang NP. Resonance frequency analysis in relation to jawbone characteristics and during early healing of implant installation. Clin Oral Implants Res. 2007;18(3):275-80.

43. Simunek A, Kopecka D, Brazda T, Strnad I, Capek L, Slezak R. Development of implant stability during early healing of immediately loaded implants. Int $\mathrm{J}$ Oral Maxillofac Implants. 2012;27(3):619-27.

44. Park KJ, Kwon JY, Kim SK, Heo SJ, Koak JY, Lee JH, Lee SJ, Kim TH, Kim MJ. The relationship between implant stability quotient values and implant insertion variables: a clinical study. J Oral Rehabil. 2012 Feb;39(2):151-9.

45. Manresa C, Bosch M, Echeverría JJ. The comparison between implant stability quotient and bone - implant contact revisited: an experiment in Beagle dog. Clinical oral implants research. 2014;25(11):1213-21. 
46. Chong L, Khocht A, Suzuki JB, Gaughan J. Effect of implant design on initial stability of tapered implants. J Oral Implantol. 2009;35(3):130-5.

47. Lachmann S, Laval JY, Axmann D, Weber H. Influence of implant geometry on primary insertion stability and simulated peri-implant bone loss: an in vitro study using resonance frequency analysis and damping capacity assessment. Int $\mathrm{J}$ Oral Maxillofac Implants. 2011;26(2):347-55.

48. Karl M, Irastorza-Landa A. Does implant design affect primary stability in extraction sites? Quintessence Int. 2017;48(3):219-224.

49. Lang NP, Salvi GE, Huynh-Ba G, Ivanovski S, Donos N, Bosshardt DD. Early osseointegration to hydrophilic and hydrophobic implant surfaces in humans. Clin Oral Implants Res. 2011;22(4):349-56.

50. Rupp F, Gittens RA, Scheideler L, Marmur A, Boyan BD, Schwartz Z, et al. A review on the wettability of dental implant surfaces I: theoretical and experimental aspects. Acta Biomater. 2014;10(7):2894-906.

51. Gittens RA, Olivares-Navarrete R, Cheng A, Anderson DM, McLachlan T, Stephan I, et al. The roles of titanium surface micro/nanotopography and wettability on the differential response of human osteoblast lineage cells. Acta Biomater. 2013;9(4):6268-77.

52. Zinelis S, Silikas N, Thomas A, Syres K, Eliades G. Surface characterization of SLActive dental implants. Eur J Esthet Dent. 2012;7(1):72-92.

53. Roccuzzo M, Wilson TG, Jr. A prospective study of 3 weeks' loading of chemically modified titanium implants in the maxillary molar region: 1-year results. Int J Oral Maxillofac Implants. 2009;24(1):65-72.

54. Wennerberg A, Jimbo R, Stubinger S, Obrecht M, Dard M, Berner S. Nanostructures and hydrophilicity influence osseointegration: a biomechanical study in the rabbit tibia. Clin Oral Implants Res. 2014;25(9):1041-50.

55. Guler AU, Sumer M, Duran I, Sandikci EO, Telcioglu NT. Resonance frequency analysis of 208 Straumann dental implants during the healing period. J Oral Implantol. 2013;39(2):161-7. 
56. Han J, Lulic M, Lang NP. Factors influencing resonance frequency analysis assessed by Osstell mentor during implant tissue integration: II. Implant surface modifications and implant diameter. Clin Oral Implants Res. 2010;21(6):605-11.

57. Oates TW, Valderrama $P$, Bischof $M$, Nedir $R$, Jones $A$, Simpson J, et al. Enhanced implant stability with a chemically modified SLA surface: a randomized pilot study. Int J Oral Maxillofac Implants. 2007;22(5):755-60.

58. Schätzle $M$, Männchen $R$, Balbach $U$, Hämmerle $\mathrm{CH}$, Toutenburg $\mathrm{H}$, Jung RE. Stability change of chemically modified sandblasted/acid - etched titanium palatal implants. A randomized - controlled clinical trial. Clinical oral implants research. 2009;20(5):489-95.

59. Rossi F, Lang NP, Ricci E, Ferraioli L, Marchetti C, Botticelli D. Early loading of 6-mm-short implants with a moderately rough surface supporting single crowns--a prospective 5-year cohort study. Clin Oral Implants Res. 2015 Apr;26(4):471-7.

60. Hicklin SP, Schneebeli E, Chappuis V, Janner SF, Buser D, Bragger U. Early loading of titanium dental implants with an intra-operatively conditioned hydrophilic implant surface after 21 days of healing. Clin Oral Implants Res. 2016;27(7):875-83.

61. Marković A, Dinić A, Calvo Guirado JL, Tahmaseb A, Sćepanović M, Janjić B. Randomized clinical study of the peri-implant healing to hydrophilic and hydrophobic implant surfaces in patients receiving anticoagulants. Clin Oral Implants Res. 2017 Oct;28(10):1241-1247

62. Donos N, Horvath A, Mezzomo LA, Dedi D, Calciolari E, Mardas N. The role of immediate provisional restorations on implants with a hydrophilic surface: A randomised, single-blind controlled clinical trial. Clin Oral Implants Res. 2017 Aug 21.

63. Lekholm UZ, G.A. . Patient selection and preparation. In: Group. QIP, editor. Branemark, P-I, Zarb, GA \& Albrektsson, T Tissue Integrated Prosthesis Osseointegration in Clinical Dentistry. Chigaco:1985; 199-210.

64. Abrahamsson I, Berglundh T, Linder E, Lang NP, Lindhe J. Early bone formation adjacent to rough and turned endosseous implant surfaces. An experimental study in the dog. Clin Oral Implants Res. 2004;15(4):381-92.

65. Novellino MM, Sesma N, Zanardi PR, Laganá DC. Resonance frequency analysis of dental implants placed at the posterior maxilla varying the surface 
treatment only: A randomized clinical trial. Clin Implant Dent Relat Res. 2017 Oct;19(5):770-775. 


\section{AVALIAÇÃO DA ESTABILIDADE DE IMPLANTES COM DOIS DIFERENTES TRATAMENTOS DE SUPERFÍCIE: ENSAIO CLÍNICO RANDOMIZADO}

Marcelo M. Novellino, Profa. Dra. Dalva Cruz Laganá, Prof. Dr. Newton Sesma.

Centro de Excelência em Prótese e Implantes da FO - USP (CEPI - FOUSP) Local: Clínica Odontológica da FO- USP - Cidade Universitária - São Paulo - SP

Prezado(a) Senhor(a):

Gostaríamos de convidá-lo (a) de forma voluntária a participar da pesquisa “AVALIAÇÃO DA ESTABILIDADE DE IMPLANTES COM DOIS DIFERENTES TRATAMENTOS DE SUPERFÍCIE: ENSAIO CLÍNICO RANDOMIZADO”, realizada no Centro de Excelência em Prótese e Implante da Faculdade de Odontologia da USP/ São Paulo. A sua participação é voluntária e o seu consentimento para participação da pesquisa pode ser retirado a qualquer momento sem prejuízo para o seu tratamento.

O objetivo da pesquisa é comparar a fixação (estabilidade) de implantes com uma determinada superfície (superfície tratada por jateamento com partículas abrasivas e subtração ácida (Neoporos)) com implantes com outro tipo de tratamento superficial (hidrofílica (química) e com maior energia de superfície (Acqua)) em um período de 16 semanas após instalação. Os implantes empregados nesta pesquisa são normalmente utilizados em clínicas e consultórios e são aprovados por órgãos públicos responsáveis. 
A sua participação é muito importante e ela se daria da seguinte forma, o senhor(a) será submetido a cirurgia para a colocação de implantes em região desdentada posterior da maxila (maxilar superior) e fará avaliação deste implante por meio de uma aparelho que mede a qualidade e a quantidade da fixação deste ao seu osso por um período de 16 semanas.

Os riscos e desconfortos que podem lhe afetar são os inerentes ao procedimento cirúrgico para a colocação de implantes dentários e cirurgias orais menores, ou seja, os mesmos riscos e desconfortos que poderiam acontecer em qualquer cirurgia para a colocação de implantes, sendo este o tratamento que foi previamente eleito para o seu caso. No entanto todos podem ser controlados e atenuados pela equipe que é bastante experiente. $\mathrm{O}$ risco de perder o implante após a sua colocação existe, mas este pode ser refeito em outra oportunidade se possível, dependendo da qualidade óssea. Para a pesquisa propriamente dita, os riscos e desconfortos são mínimos, semelhantes ao de um exame clínico convencional, já que apenas tomaremos a medida da fixação do implante por meio de um aparelho que mede a vibração do implante. Todo o processo foi idealizado para não prejudicar o implante instalado.

As consultas são normalmente de 1 hora, nas fases iniciais faremos atividades que visam o diagnóstico e o planejamento cirúrgico para a colocação dos implantes. A cirurgia pode ser mais demorada em virtude do número de implantes a serem colocados, por volta de 2 horas de consulta. Os procedimentos de coleta de dados e pós- operatório são rápidos e as consultas de devem durar 30 minutos. Por volta de 15 sessões (consultas), incluindo a parte da pesquisa, deverão ser necessárias para a realização de todas as etapas: planejamento prévio (3 sessões), a cirurgia (1 sessão), pós operatório (1 sessão) e coleta de dados (10 sessões), sendo que nestas últimas não haverá qualquer tipo de desconforto ou dor, apenas será realizada a medição com o aparelho.

Os benefícios esperados são: (1) para o meio científico poderá consolidar avaliações feitas em laboratório (in vitro) e em animais quanto a maior velocidade de ósteointegração (adesão do implante ao osso) dos novos tratamentos de superfícies existentes. (2) para o senhor saber se o implante instalado aderiu (osteointegrou) bem, além de ganhar os implantes.

As informações serão utilizadas somente para os fins desta pesquisa e serão tratadas com o mais absoluto sigilo e confidencialidade, de modo a preservar a sua identidade. 
A sua participação é totalmente voluntária, podendo você: recusar-se a participar, ou mesmo desistir a qualquer momento sem que isto acarrete qualquer ônus ou prejuízo à sua pessoa.

Gostaríamos de saber se o(a) senhor(a) autoriza a utilização dos dados coletados em outras pesquisas:

( ) NÃO autorizo.

( ) SIM autorizo a utilização em outra pesquisas dos dados coletados.

Para a utilização dos dados coletados em outra pesquisa o (a) senhor(a) gostaria de ser consultado:

( ) NÃO quero ser consultado da utilização dos dados coletados em outra pesquisa, desde que a nova pesquisa seja aprovada pelo Comitê de Ética em Pesquisa.

( ) SIM quero ser consultado da utilização dos dados coletados em outra pesquisa

Informamos que o(a) senhor(a) não pagará nem será remunerado por sua participação. Tanto a prótese, quanto exames e medicamentos necessários para a colocação dos implantes serão arcados pelo próprio paciente, pois não são parte da pesquisa. A prótese poderá ser realizada na clínica do CEPI, que acontece todas as quintas feiras pela manhã e custo do tratamento protético tem valor abaixo do mercado sendo apenas o custo de laboratório e componentes protéticos. As radiografias e tomografias podem ser realizadas na Fundecto também com custo reduzido.

Caso o(a) senhor(a) tenha dúvidas, necessite esclarecimentos ou assistência pode nos contatar: Marcelo M. Novellino, CEPI - FOUSP, xxxxxxxxxxxx@gmail.com ou (11) xxxxxxxxxx.

Se houver dúvidas sobre a ética da pesquisa entre em contato com o Comitê de Ética em Pesquisa da Faculdade de Odontologia ( Av. Lineu Prestes, 2227, 05508000 São Paulo, telefone 30917960 ou pelo email cepfo@usp.br.

Após ter sido informado e ter minhas dúvidas suficientemente esclarecidas pelo pesquisador concordo em participar de forma voluntária desta pesquisa. 
São Paulo, de de 201_.

(Nome)

(Assinatura)

RG:

Pesquisador Responsável (Orientado)

Marcelo M. Novellino (CROSP: xxxxx) (RG: xxxxxxx)

Pesquisadores (Orientadores)

Profa. Dra. Dalva Cruz Laganá (CROSP:xxxxx) (RG:xxxxxxx ）

Prof. Dr. Newton Sesma (CROSP: xxxxx) (RG: xxxxxxxxx ) 
ANEXO B - Aprovação junto ao Comitê de Ética em Pesquisa (CEP)

FACULDADE DE
ODONTOLOGIA DA
UNIVERSIDADE DE SÃO Platorforma

DADOS DA EMENDA

Título da Pesquisa: Avaliação da estabilidade de implantes com dois diferentes tratamentos de superfície: ensaio clínico randomizado

Pesquisador: Marcelo Michele Novellino

Área Temática:

Versão: 3

CAAE: 18911913.7 .0000 .0075

Instituição Proponente: Universidade de Sao Paulo

Patrocinador Principal: Universidade de Sao Paulo

DADOS DO PARECER

Número do Parecer: 1.433 .650

\section{Apresentação do Projeto:}

Os pesquisadores citam: O aprimoramento tecnológico vivido pela implantodontia nos últimos anos trouxeram facilidades e sobretudo resultados melhores a longo prazo. Os tratamentos de superfície não fugiram a essa regra e hoje temos opções no mercado capazes de reduzir o tempo de osteointegração e aperfeiçoá-la. Nesta pesquisa pacientes que contemplarem os critérios de inclusão e não os de exclusão receberão 84 implantes, sendo 42 com superfície convencional (jateamento e ataque ácido) e 42 com superfície quimicamente modificada. Os implantes serão submetidos à avaliação por meio de análise de freqüência de ressonância imediatamente após a instalação do implante (baseline) e nas sessões de acompanhamento $\left(1^{\mathrm{a}}, 2^{\mathrm{a}}, 3^{\mathrm{a}}, 5^{\mathrm{a}}, 8^{\mathrm{a}}, 12^{\mathrm{a}}\right.$ e $16^{\mathrm{a}}$ semanas após instalação) e o coeficiente de estabilidade do implante (ISQ) será medido nessas datas, em uma escala de 0 a 100 . Os resultados obtidos serão submetidos à análise estatística (análise de variância de medidas repetidas) com nível de significância a 5\% e a hipótese é de que implantes com superfície quimicamente modificada apresentem osteointegração mais rápida e melhor.

Objetivo da Pesquisa:

Objetivos primário: Comparar a estabilidade de implantes de superfície tratada por jateamento com partículas abrasivas e subtração ácida (Neoporos) com implantes de superfície hidrofílica

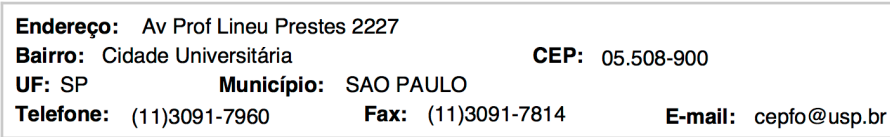




\section{FACULDADE DE ODONTOLOGIA DA UNIVERSIDADE DE SÃO}

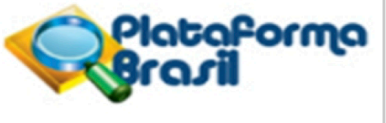

Continuação do Parecer: 1.433 .650

(química) e com maior energia de superfície (Acqua) em um período de 16 semanas após instalação. Objetivo Secundário: O objetivo específico desse ensaio clínico randomizado será comparar a estabilidade de implantes de superfície tratada com jateamento de partículas abrasivas e ataque ácido com implantes de superfície hidrofílica em um período de 16 semanas após instalação, através da análise de frequência de ressonância. A hipótese a ser testada será a de que implantes com superfície hidrofílica apresentem aumento da estabilidade secundária anteriormente aos implantes tratados por ataque ácido.

\section{Avaliação dos Riscos e Benefícios:}

Os pesquisadores citam que os riscos são os inerentes aos procedimentos que envolvem as cirurgias orais menores e a reabilitação oral por meio de implantes osseointegrados, sendo este o tratamento previamente eleito para o paciente. $O$ risco de perder o implante após a sua colocação existe, mas este pode ser refeito em outra oportunidade se possível, dependendo da qualidade e quantidade de tecido ósseo. Para a pesquisa propriamente dita, os riscos e desconfortos são mínimos, semelhantes ao de um exame clínico convencional, já que apenas tomaremos a medida da estabilidade do implante por meio do Ostell. Todo o processo foi idealizado para não prejudicar o implante instalado, já que o smartpeg (componente que ressona a frenquência emitida pelo aparelho Ostell) vai rosqueado ao cicatrizador sem gerar torque no implante. Portanto a pesquisa em si, não considerando a colocação dos implantes, oferece riscos baixíssimos ao paciente. Benefícios: Os sujeitos da pesquisa não receberão nenhum benefício (Ganharão os implantes), propriamente dito, direto da pesquisa. Apenas poderão ser informados quanto a estabilidade de seus implantes, durante o período de avaliação. Este fato, apesar de ser algo desnecessário para a evolução do tratamento, na clínica diária é frequentemente questionado pelos pacientes, podendo assim ser considerado como benefício. Entretanto para o meio científico poderá consubstanciar avaliações in vitro e em animais quanto a maior velocidade de osteointegração dos novos tratamentos de superfícies existentes.O paciente poderá dar continuidade a seu tratamento protético na própria clínica do Centro de Excelência em Prótese e Implante do Departamento de Prótese Dentária da Faculdade de Odontologia da USP (CEPI-FOUSP).

\section{Comentários e Considerações sobre a Pesquisa:}

Os pesquisadores solicitam uma emenda, justificando que "a emenda se faz necessária pois decidimos realizar o acompanhamento dos implantes instalados para obter dados sobre a sobrevida e o sucesso dos mesmos pelo período de um ano após a cirurgia de instalação. Esses dados são importantes para a pesquisa e não afetam o tratamento prestado aos pacientes. Estes ainda poderão ter o benefício da avaliação da saúde de seus implantes e o encaminhamento para

Endereço: Av Prof Lineu Prestes 2227

$\begin{array}{lll}\text { Bairro: Cidade Universitária } & \text { CEP: } & 05.508-900 \\ \text { UF: SP } & \text { Município: SAO PAULO }\end{array}$

Telefone: (11)3091-7960 Fax: (11)3091-7814 E-mail: cepfo@usp.br 


\section{FACULDADE DE ODONTOLOGIA DA UNIVERSIDADE DE SÃO}

Continuação do Parecer: 1.433.650

tratamento de qualquer intercorrência com os mesmos, tais como periimplantites, mobilidade e radiolucência ao redor do implante."

Complementam "Os implantes e cicatrizadores foram doados pela empresa Neodent. Os kits cirúrgicos e o aparelho Ostell foram cedidos por empréstimo pela mesma empresa (Neodent). Decidimos fazer o follow up dos implantes instalados após um ano por meio de exame clínico (mobilidade sondagem) e radiográfico (periapicais) e por isso solicitamos essa emenda do parecer já aprovado."

\section{Considerações sobre os Termos de apresentação obrigatória:}

Apresenta:

Carta de autorização para uso da clínica.

TCLE.

Folha de rosto,

Projeto detalhado.

\section{Recomendações:}

Tendo em vista a legislação vigente, devem ser encaminhados ao CEP-FOUSP relatórios parciais anuais referentes ao andamento da pesquisa e relatório final, utilizando-se da opção "Enviar Notificação" (descrita no Manual "Submeter Notificação", disponível na Central de Suporte - canto superior direito do site www.saude.gov.br/plataformabrasil).

Qualquer alteração no projeto original deve ser apresentada "emenda" a este CEP, de forma objetiva e com justificativas para nova apreciação.

Conclusões ou Pendências e Lista de Inadequações:

Emenda aprovada.

Considerações Finais a critério do CEP:

Este parecer foi elaborado baseado nos documentos abaixo relacionados:

\begin{tabular}{|l|l|c|c|c|}
\hline \multicolumn{1}{|c|}{ Tipo Documento } & \multicolumn{1}{|c|}{ Arquivo } & Postagem & Autor & Situação \\
\hline $\begin{array}{l}\text { Informações Básicas } \\
\text { do Projeto }\end{array}$ & PB_INFORMAÇÕES_BÁSICAS_658658 & $02 / 02 / 2016$ & & Aceito \\
\hline Folha de Rosto & E1.pdf & $12 / 11 / 2013$ & & \\
& Folha de Rosto.pdf & $12: 11: 29$ & & Aceito \\
\hline
\end{tabular}

Endereço: Av Prof Lineu Prestes 2227

Bairro: Cidade Universitária

UF: SP Município: SAO PAULO

Telefone: (11)3091-7960 Fax: (11)3091-7814 E-mail: cepfo@usp.br

Telefone: (11)3091-7960 Fax: (11)3091-7814 E-mail: cepfo@usp.br

CEP: $05.508-900$ 


\section{FACULDADE DE ODONTOLOGIA DA UNIVERSIDADE DE SÃO}

Platoforma Brasil

Continuação do Parecer: 1.433.650

\begin{tabular}{|l|l|c|l|c|}
\hline Projeto Detalhado / & Projeto Acqua - CEP.docx & $12 / 11 / 2013$ & & Aceito \\
Brochura & & $11: 17: 45$ & & \\
Investigador & & $12 / 11 / 2013$ & & Aceito \\
\hline TCLE / Termos de & Termo de Consentimento Livre & $11: 17: 12$ & & \\
Assentimento / & Esclarecido.doc & & & \\
Justificativa de & & $24 / 07 / 2013$ & & Aceito \\
\hline Ausência & & $21: 27: 34$ & & \\
\hline Outros & Liberação da Clínica.pdf & & & \\
\hline
\end{tabular}

Situação do Parecer:

Aprovado

Necessita Apreciação da CONEP:

Não

SAO PAULO, 02 de Março de 2016

Assinado por:

Maria Gabriela Haye Biazevic

(Coordenador) 


\section{ClinicalTrials.gov PRS}

Protocol Registration and Results System

ClinicalTrials.gov Protocol and Results Registration System (PRS) Receipt Release Date: 05/26/2015

\section{Evaluation of the Stability of Implants With Two Different Surface Treatments}

This study is ongoing, but not recruiting participants.

\begin{tabular}{|r|c|}
\hline Sponsor: & University of Sao Paulo \\
\hline Collaborators: & \\
\hline $\begin{array}{r}\text { Information provided by } \\
\text { (Responsible Party): }\end{array}$ & Marcelo Michele Novellino, University of Sao Paulo \\
\hline ClinicalTrials.gov Identifier: & NCT02134743 \\
\hline
\end{tabular}

\section{Purpose}

The aim of this study is to compare the stability of dental implant surface treated by sandblasting abrasive particles and acid subtraction (Control) with hydrophilic surfaces dental implants (chemical) and with a higher surface energy (Test) for a period of 16 weeks after installation. The evaluation will be made by analyzing the resonance frequency (Ostell). The hypothesis to be tested will be that implants with hydrophilic surface show increased secondary stability prior to the implants treated by acid etching.

\begin{tabular}{|l|l|l|}
\hline Condition & Intervention & Phase \\
\hline $\begin{array}{l}\text { Dental Implant Failed } \\
\text { Pre-osseointegration Failure of Dental } \\
\text { Implant }\end{array}$ & Procedure/Surgery: Implant surgery & N/A \\
\hline
\end{tabular}

Study Type: Interventional

Study Design: Parallel Assignment, Double Blind (Subject, Outcomes Assessor), Randomized, N/A

Official Title: Evaluation of the Stability of Implants With Two Different Surface Treatments: a Randomized Clinical Trial

Further study details as provided by Marcelo Michele Novellino, University of Sao Paulo:

Primary Outcome Measure:

- Loss of implant [Time Frame: 4 months after surgery] [Designated as safety issue: Yes] If the implant has been not integrated to the bone!

Secondary Outcome Measures:

- Implant stability (ISQ) [Time Frame: Baseline, 1 to 16 weeks (4 months)] [Designated as safety issue: Yes] If the implant get successively and it has been integrated to bone. The stability will be evaluated at the surgery day (T0), one week after surgery (T1),after 2 weeks (T2), after 3 weeks (T3), after 5 weeks (T4), after 8 weeks (T5), after 12 weeks (T6) and after 16 weeks (T7)

Enrollment: 21

Study Start Date: April 2014

Estimated Primary Completion Date: July 2015

Estimated Study Completion Date: December 2015 
ANEXO D - Tabela que foi utilizada para a coleta de dados

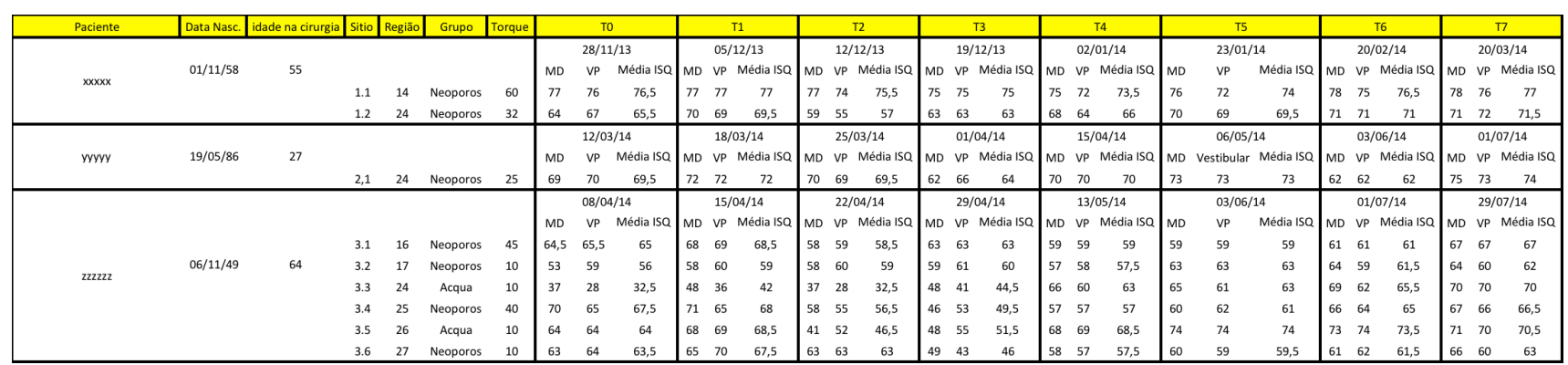


ANEXO E - Artigo Publicado na Clinical Implant Dentistry and Related Research (Qualis A1) (65). O artigo completo está disponível pelo site do Pubmed com acesso livre (Open Access)

\begin{tabular}{l|l|l} 
Received: 8 February 2017 & Revised: 22 May 2017 & Accepted: 24 May 2017 \\
\hline DOl: 10.1111/cid.12510 & & \\
O R I G I N A L A R T I C LE & WI LEY
\end{tabular}

\title{
Resonance frequency analysis of dental implants placed at the posterior maxilla varying the surface treatment only: A randomized clinical trial
}

\author{
Marcelo M. Novellino, DDS, MSc, PhD 이 ～Newton Sesma, DDS, MSD, PhD । \\ Piero R. Zanardi, DDS, MSc, PhD | Dalva C. Laganá, DDS, MSD, PhD
}

Department of Prosthodontics, School of Dentistry, University of São Paulo, São

Paulo, Brazil

Correspondence

Marcelo Michele Novellino, Departamento

de Prótese, Universidade de São Paulo,

Prof. Lineu Prestes avenue 2227, São Paulo

05508-000, Brazil.

Email: mmnovellino@gmail.com

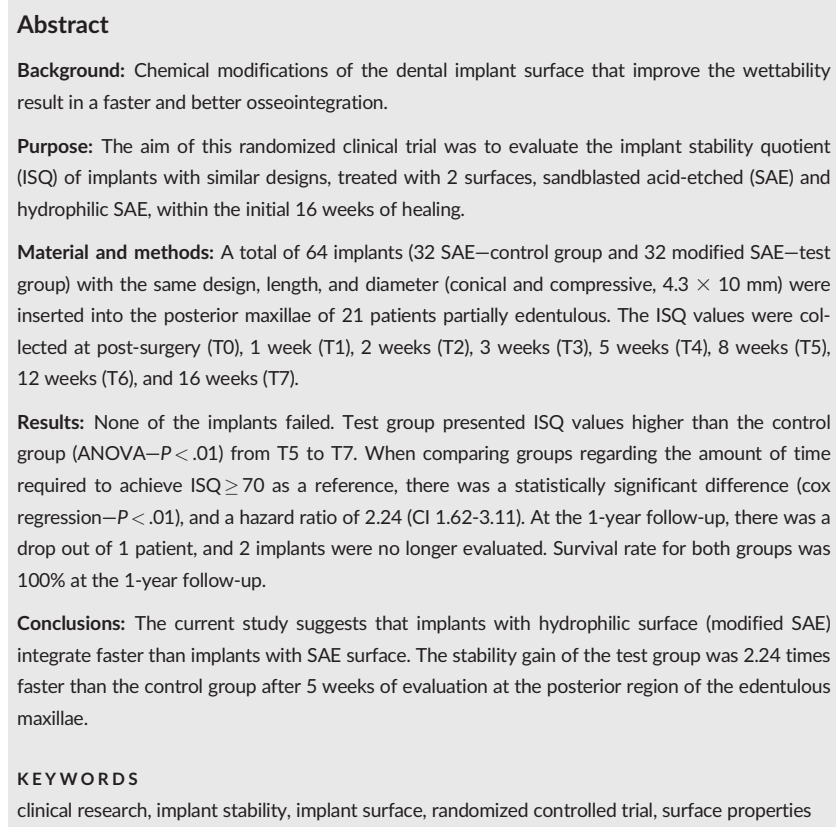

Background: Chemical modifications of the dental implant surface that improve the wettability result in a faster and better osseointegration.

Purpose: The aim of this randomized clinical trial was to evaluate the implant stability quotient (ISQ) of implants with similar designs, treated with 2 surfaces, sandblasted acid-etched (SAE) and hydrophilic SAE, within the initial 16 weeks of healing

Material and methods: A total of 64 implants (32 SAE-control group and 32 modified SAE-test group) with the same design, length, and diameter (conical and compressive, $4.3 \times 10 \mathrm{~mm}$ ) were inserted into the posterior maxillae of 21 patients partially edentulous. The ISQ values were collected at post-surgery (T0), 1 week (T1), 2 weeks (T2), 3 weeks (T3), 5 weeks (T4), 8 weeks (T5), 12 weeks (T6), and 16 weeks (T7)

Results: None of the implants failed. Test group presented ISQ values higher than the control group (ANOVA $-P<.01$ ) from $T 5$ to $T 7$. When comparing groups regarding the amount of time required to achieve ISQ $\geq 70$ as a reference, there was a statistically significant difference (cox regression $-P<.01$ ), and a hazard ratio of 2.24 (Cl 1.62-3.11). At the 1-year follow-up, there was a drop out of 1 patient, and 2 implants were no longer evaluated. Survival rate for both groups was $100 \%$ at the 1 -year follow-up.

Conclusions: The current study suggests that implants with hydrophilic surface (modified SAE) integrate faster than implants with SAE surface. The stability gain of the test group was 2.24 times faster than the control group after 5 weeks of evaluation at the posterior region of the edentulous maxillae.

KEYWORDS

clinical research, implant stability, implant surface, randomized controlled trial, surface properties

\section{1 | INTRODUCTION}

Studies have proved that implants with treated surfaces, such as sandblasted and acid-etched (SAE), result in faster osseointegration compared to implants with machined surfaces. ${ }^{1,2}$ Also, chemical modifications used to improve the wettability of such surfaces result in faster osseointegration. ${ }^{1,3}$ The wettability of a clean hydrophilic titanium oxide surface is obtained by an extensive hydroxylation/hydration of 